\title{
Friction related size-effect in microforming - a review
}

\author{
Chunju Wang ${ }^{1,2, *}$, Bin Guo ${ }^{1}$, and Debin Shan $^{1}$ \\ 1 School of Materials Science and Engineering, Harbin Institute of Technology, Harbin 150001, China \\ 2 Department of Design, Manufacturing and Engineering Management, The University of Strathclyde, Glasgow G1 1XJ, UK
}

Received 27 October 2014 / Accepted 27 December 2014

\begin{abstract}
This paper presents a thorough literature review of the size effects of friction in microforming. During miniaturization, the size effects of friction occur clearly. The paper first introduces experimental research progress on size effects of friction in both micro bulk and sheet forming. The effects of several parameters are discussed. Based on the experimental results, several approaches have been performed to develop a model or functions to analyse the mechanism of size effects of friction, and simulate the micro deep drawing process by integrating them into an FE program. Following this, surface modification, e.g. a DLC film and a micro structure/textured surface, as a method to reduce friction are presented. Finally, the outlook for the size effect of friction in the future is assessed, based on the understanding of the current research progress.
\end{abstract}

Key words: Microforming, Friction, Size effects, Models, Surface modification

\section{Introduction}

Product miniaturization is an emerging trend for facilitating product usage, enabling unique product functions to be implemented in micro-scaled geometries and features, and further reducing product weight and volume. Recently, the demand for micro-parts has increased significantly in many industry clusters. Development of advanced micro-manufacturing technologies for the fabrication of such micro-parts has thus become a critical issue. From the viewpoint of production engineering, microforming, which offers attractive characteristics including high productivity, low cost and good quality of the formed parts, provides a promising approach to the fabrication of metallic micro-parts $[1,2]$. Compared to other manufacturing technologies, microforming features specific economical and ecological advantages [3-5]. However, if during the miniaturization of parts, the microstructure and surface roughness of the specimens are held constant, the so-called size effects occur in microforming processes. The key problems, size effects, characterizing the micro-world are identified as the effects of miniaturization on the material, the process, the tool and the machine $[6,7]$. The specific advantages of metal forming cannot be exploited to the same extent as that in conventional metal forming [8]. Numerous basic research projects have been carried out to reveal the nature and mechanism of size effects with experiments scaled down according to similarity theory. For example, the size effects on flow stress and filling ability have been investigated by considering the

*e-mail: cjwang1978@hit.edu.cn polycrystalline structure of metallic materials and the boundary conditions in plastic deformation using micro-compression tests and coining experiments [9]. Another kind of miniaturization effect is the size effect of friction. The tribological conditions between the tool and the workpiece in metal working are of greatest importance for process feasibility and process quality, and this is even truer when the process is scaled down from conventional dimensions down to micro dimensions. Due to the high ratio of the free surface-to-volume of micro-parts, and the surface topography of the specimens being held constant, friction has more effect on metallic forming processes than that in traditional macro metal forming. In recent years, many investigations on the size effects of friction have been carried out on the bulk and sheet metal forming processes, and have suggested several theoretical approaches based on the mechanical-rheological model etc. to understand and describe the size effects of friction [10]. In an industrial production, the situation should be improved to reduce the effects on friction. Indeed, scaling effects not only appear within the process but also must be taken into account in all other area of the forming process chain, finally demanding new solutions, especially in respect of tool manufacturing and machine concepts [11]. Some surface coatings with good tribological properties, e.g. diamond-like carbon (DLC), and micro structured/ textured surface tools have been applied in microforming processes to obtain high process qualities $[12,13]$. Although there were efforts made to realize microforming for industrial application, the technology itself was seen as being insufficiently mature. Much development work needed to be done [14]. Therefore, to conclude the paper, the situation in respect of 
the size effect of friction in the future is assessed, based on the understanding of the current research progress.

\section{Experimental investigation on size effects of friction in microforming}

For the high contact pressure at the interface between the tool and the workpiece, the tribological behaviour play an important role in metal forming, especially in microforming. Many experimental investigations on frictional size effects have been performed both in micro bulk forming and micro sheet forming for different microforming process characteristics.

\subsection{Size effects of friction in micro bulk forming}

In metal forming processes, ring compression tests are often used to evaluate the coefficient of friction by determining the relationship between the change of the internal and outer diameters, and the reduction of height. Using ring specimens of different dimensions, Messner et al. performed ring compression tests to investigate the size effects of friction. Some specimens were compressed without interruption to the intended reduction of height and the changes of the inner and outer diameter are measured for different angles to the grinding direction with a measuring microscope. The experimental data of the internal diameter show an increase of the interfacial friction coefficient with decreasing specimen dimensions (from $\mu \approx 0.12$ for $D=4.8 \mathrm{~mm}$ to $\mu \approx 0.22$ for $D=1.0 \mathrm{~mm}$ ). The comparison of the outer diameters indeed confirms the range of the friction coefficients determined by the internal diameters, but the size effect expected from the internal diameters is not observable. In some cases, the results show no significant dependency between the tribological behaviour and the specimen dimensions. The reason may be that the effect of the sliding length, which is different for the tested specimen and dimensions, and the flow behaviour is too small to affect the measurable change of the specimen diameters $[15,16]$.

The scaled double-cup extrusion (DCE) process was preferred to clearly evaluate the change of friction, which was characterized by a larger increase in the surface area, larger strains and higher pressure between the specimen and the die. As shown in Figure 1, the higher is the friction, the more the forming of the lower cup is prevented. Therefore, the ratio $h_{\mathrm{u}} / h_{1}$ is quite a sensitive measure for friction. Using geometrically similar specimens (CuZn15) of an initial diameter of 4,2 , 1 and $0.5 \mathrm{~mm}$ with a ratio of $d_{0} / h_{0}=1$, Geiger et al. performed the experiments at room temperature on a regular testing machine with a size-adapted punch speed. For lubrication the standard extrusion oil CASTROL KPO 2098 and in one case the $\mathrm{MoS}_{2}$ Spray MOLYDUVAL was used. The results shown in Figure 2 indicate that friction increases with decreasing specimen size. The numerical identification shows a friction factor of around $m=0.02$ for $4 \mathrm{~mm}$ specimens, while it increases for the smaller specimens up to $m=0.4$. The standard deviation also shows an increase in the scatter of the results with (a)

(b)

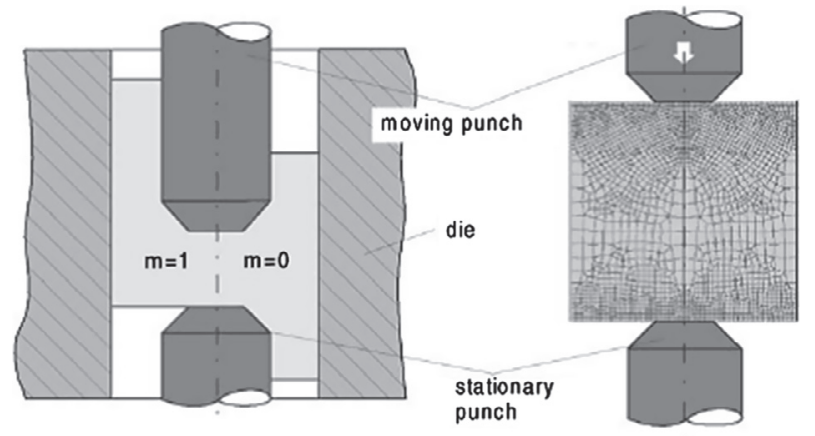

(c)

(d)
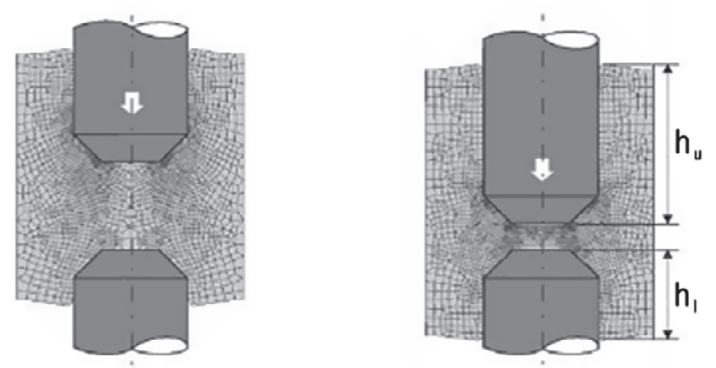

Figure 1. DCE test: (a) dependence of cup height on friction; (b)-(d) FEM calculation, showing the development of the cups [5].

decreasing specimen size. Furthermore, it can be observed that the highest friction occurs at the beginning of the process, then the friction decreases but seems to increase again at the end. The reason may be that the change from sticking to sliding friction occurs at different relative motion for different specimens. When double the punch velocity was applied, the $4 \mathrm{~mm}$ and $1 \mathrm{~mm}$ specimen showed a slight decrease in friction, which could be explained by the flow resistance of the lubricant in the open lubricant pockets. The measured surface topography of specimens before and after tests can validate the explanation. Since the solid lubricant cannot flow and drain from the surface, the size effect observed for lubrication with extrusion oil does not seem to exist when using a solid lubricant $[5,10,17-21]$ (Fig. 2).

Employing a similar method, Krishnan et al. investigated the frictional behaviours in micro-extrusion by performing a series of experiments and comparing these results and those made by FEM using the models, which both assume that the flow stress of the extruded material is constant and follows the von Mises law. Force comparisons indicate that the friction coefficient and the friction factor tend to decrease as the size of the extrude pins becomes smaller [22]. To segregate the individual influences of material response and interfacial behaviour on the micro-extrusion process, Mori et al. conducted a series of frictional experiments using a stored-energy Kolsky bar, which provides a direct measurement of the existing interfacial conditions and does not depend on material deformation behaviour. The results show that there is no statistically significant effect of the grain size, the contact pressure, and the specimen size on both the static and the dynamic friction 


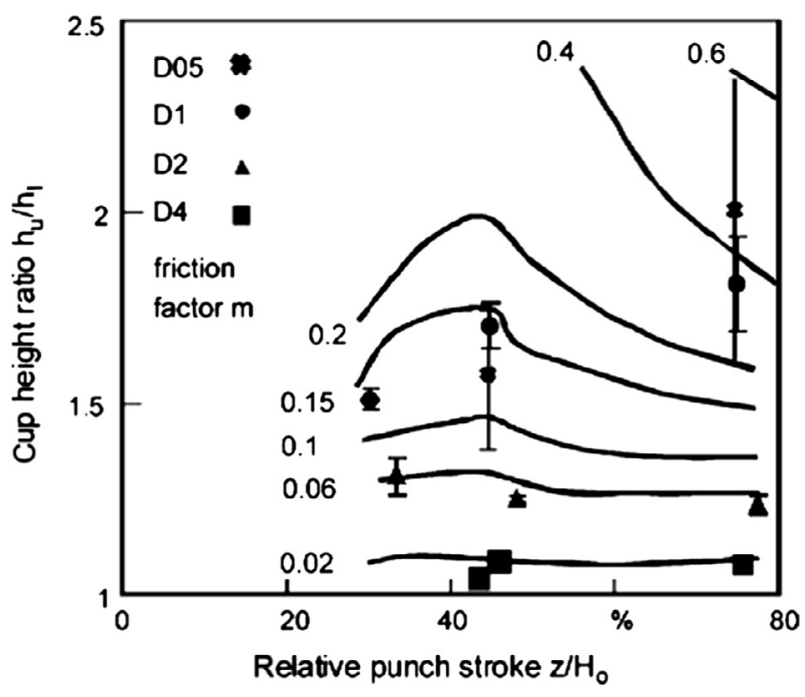

Figure 2. Experimental results, standard deviation, and curves of constant friction factor $m$ as determined by FEA $[5,10]$.

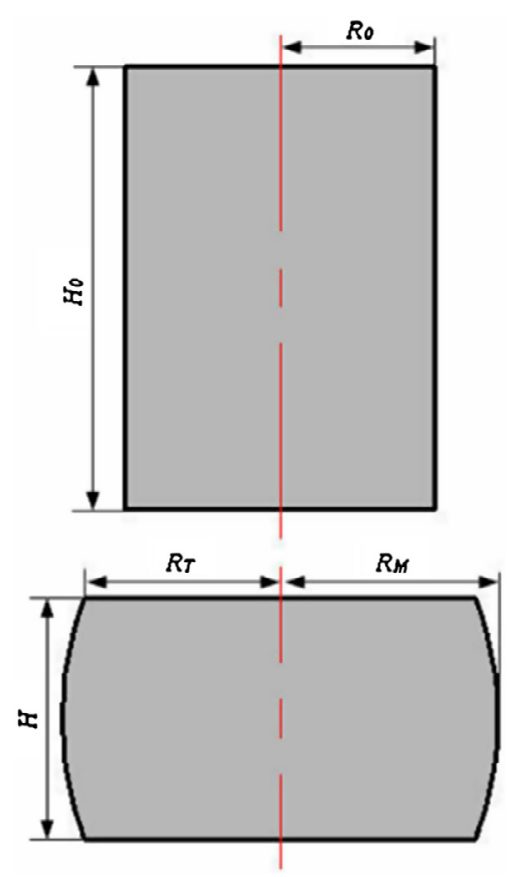

Figure 3. A schematic diagram of cylinder compression [25].

coefficients [23]. This trend is opposite to what was reported earlier. The reason is that there is an interactive effect of interfacial friction, plastic properties of micro-size material, grain size, and part size on the deformation behaviour and the micro-formed part geometry [24]. Although in comparison between the experiment and simulation results, some of them have considered the size effect of flow stress in the simulation, the small dimensions of the cavities may have an effect on the plastic deformation behaviour, which should in turn affect the results for friction factors. Since there are many difficulties in the FEA of microforming processes, it is better to find another way to determine accurately the friction factor in the future.

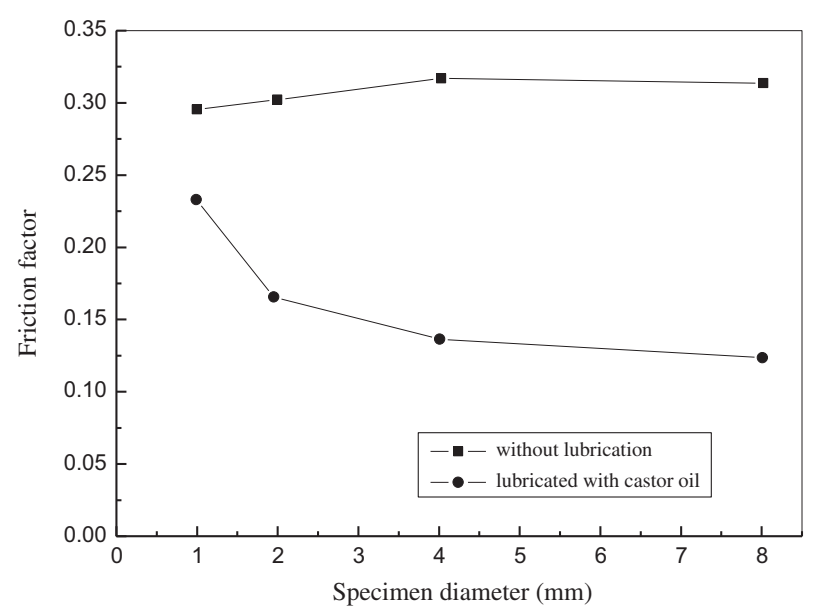

Figure 4. Friction factors of different specimens [26].

Another simple method used to determine the friction factor is cylinder compression as shown in Figure 3. The friction factor $m$ can be calculated by equation (1) obtained by the upper bound method:

$$
m=\frac{(R / H) b}{(4 / \sqrt{3})-(2 b / 3 \sqrt{3})}
$$

where $R$ is the average radius of the cylinder after deformation, $H$ is the height of cylinder after deformation, $b$ is the barrel parameter. In Guo's investigation as shown in Figure 4, it is clear that that the friction factors increased with miniaturization in the case of lubricated with castor oil. The friction factor increases by about 0.11 with miniaturization. However, in the absence of lubrication, the friction factor seems to remain constant. According to the above analysis, the tribological size effect occurred with castor-oil lubrication, but did not occur in the absence of lubrication. Figure 5a clearly shows that all of the asperities of the specimens were severely deformed and the surface topography was almost flattened for all of the specimens tested without lubrication. However, the asperities near to the edge (Fig. 5b) were severely deformed and, as in the experiments carried out without lubrication, the degree of deformation of the asperities in the inner part were much lower than those near to the edge for specimens all diameters of tested in case of using soybean oil $[25,26]$.

Other investigations were carried out by Nielsen et al. based on the symmetrical upsetting of two workpieces against an intermediate sliding tool plate, a newly designated MicroTribo-Tester (MTT), at different dimensional scales ranging from macro- to micro-forming. The results show that a friction increase is observed when going from $Ø 3 \mathrm{~mm}$ to $\varnothing 1 \mathrm{~mm}$, and a significantly larger increase is noted from $\varnothing 1 \mathrm{~mm}$ to $\varnothing 0.05 \mathrm{~mm}$. The plot indicates that size, viscosity, and tool roughness have mutual interactions with regards to their influence on friction, whereas workpiece roughness apparently only interacts with specimen size. A very finely polished tool surface may reduce the size effect and the friction as the lubricant is better retained. Higher viscosity of the lubricant reduces the size effect and friction, presumably due to the escape of lubricant being diminished. In the case of good lubrication 


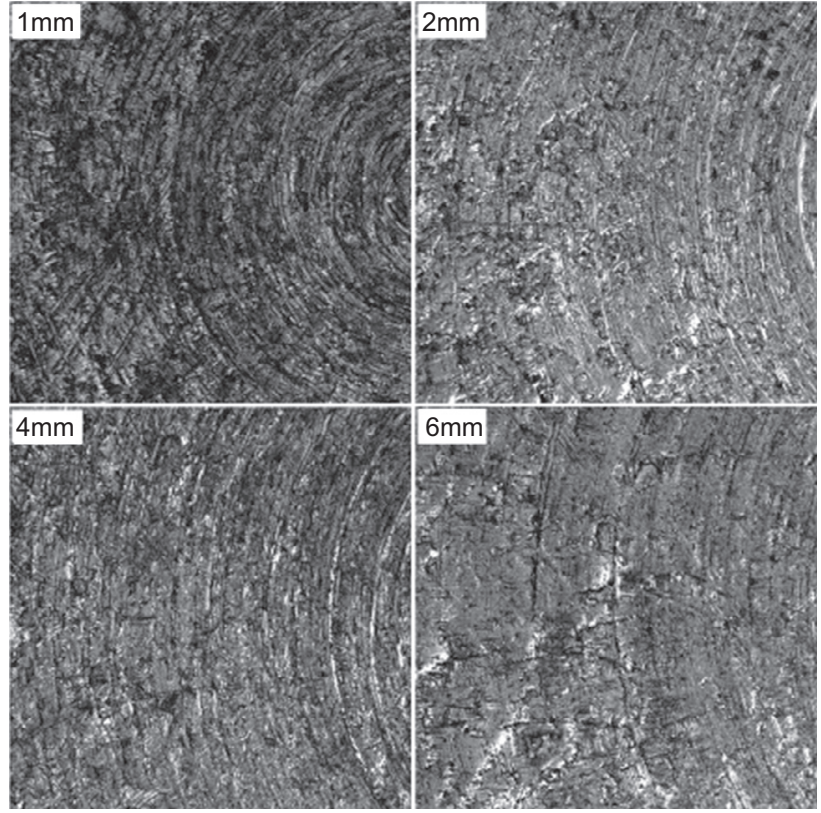

(a)

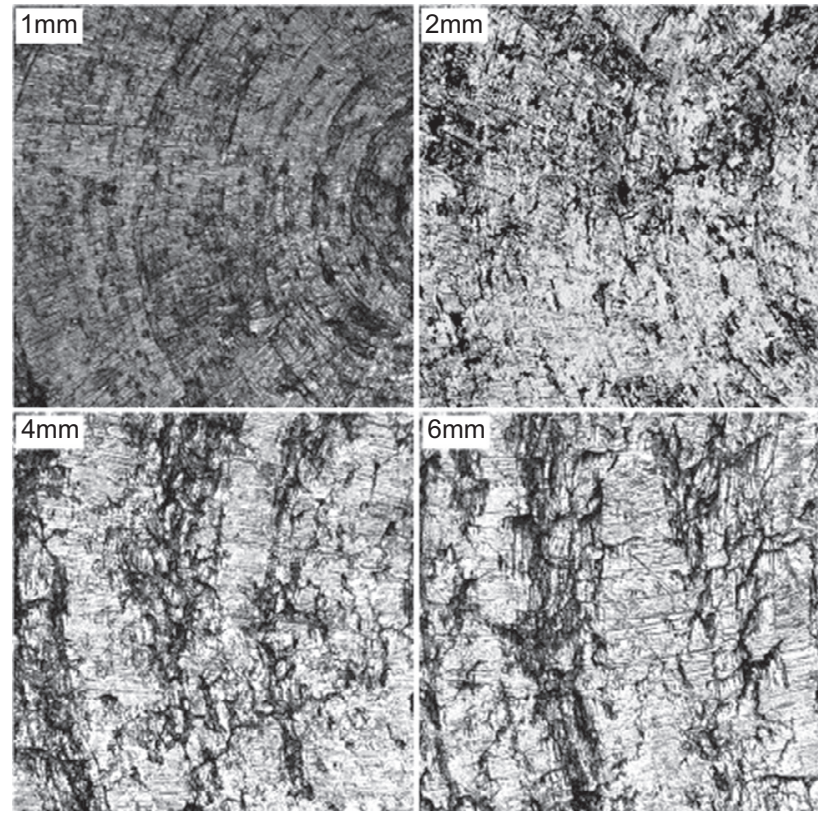

(b)

Figure 5. Surface topography of specimens after deformation annealed at $450{ }^{\circ} \mathrm{C} / 1 \mathrm{~h}$ [25]: (a) with lubricant, (b) with soybean oil.

conditions, higher viscosity may lead to higher friction for higher shear stress in the lubricant film [27].

\subsection{Size effects of friction in micro sheet forming}

Micro sheet forming processes e.g. micro deep drawing, are more sensitive to the coefficient of friction than in micro bulk forming. Strip drawing is one of very simple methods in determining the friction coefficient, as shown in Figure 6. The friction coefficient in strip drawing can be simply computed by the following equation,

$$
\mu=F /(2 N)
$$

where $\mu$ is the friction coefficient, $F$ is the friction force, and $N$ is the normal force. In accordance with similarity theory, the effect of lubricant condition on size effect is shown in Figure 7 . It can be seen that the friction coefficient without lubrication remains constant with the decrease of specimen size. However, the friction coefficients with lubrication increase clearly with decrease in specimen size. Also, it was found that the lower is the dynamic viscosity of the lubricant, the more remarkable is the size effect of friction [28].

Instead of real deep drawing, another kind of strip deep drawing was applied by $\mathrm{Hu}$ et al. in different process dimensions to discover the tribological size effects as shown in Figure 8. Thus, the tangential forces, which exist while the blank is drawn into the die, can be avoided and the stress condition is simplified. This difference makes it easier to find the relation between the punch force and the friction coefficient. From the experiment, the punch force vs. punch travel can be obtained. Within the strip drawing with deflection the punch force $F_{\text {st }}$ consists of the bending force at the radius of the die

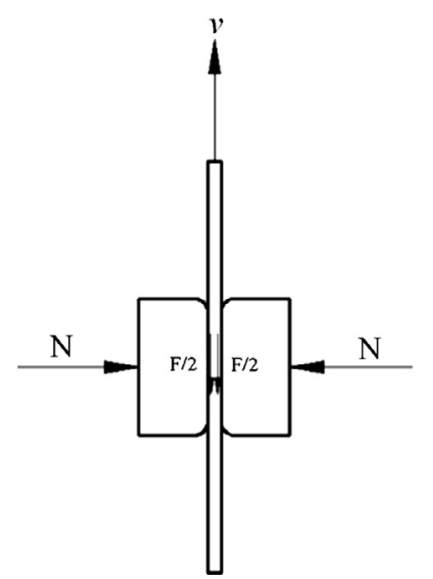

Figure 6. Schematic diagram of strip drawing [28].

and punch $F_{\mathrm{B}}$ and friction force at the flange and the radius of the die $F_{\mathrm{F}}$. For a certain workpiece bent for a certain radius the bending force can be theoretically calculated, so that the share of the friction force of the whole punch force from the strip drawing with deflection can be determined [29, 31-33].

Micro strip drawing with E-Cu58 and macro strip drawing with mild steel St14 were carried out under different blank holder forces with lubricant in different amounts (macro: $0-4 \mathrm{~g} / \mathrm{m}^{2}$; micro: without lubricant). Four different punch diameters (e.g., $100 \mathrm{~mm}, 50 \mathrm{~mm}, 20 \mathrm{~mm}$, and $1 \mathrm{~mm}$ ) were used according to the theory of similarity as shown in Figure 9. Due to the great difference of the punch forces between macroand micro-strip drawing, the experimental punch forces of different punch diameters were normalized through $F_{\mathrm{st}} /\left(b_{0} s_{0} k_{\mathrm{f}}\right)$ as shown in Figure 10, which was defined as punch travel/ punch diameter. The bigger $F_{\mathrm{st}} /\left(b_{0} s_{0} k_{\mathrm{f}}\right)$, the smaller is the 

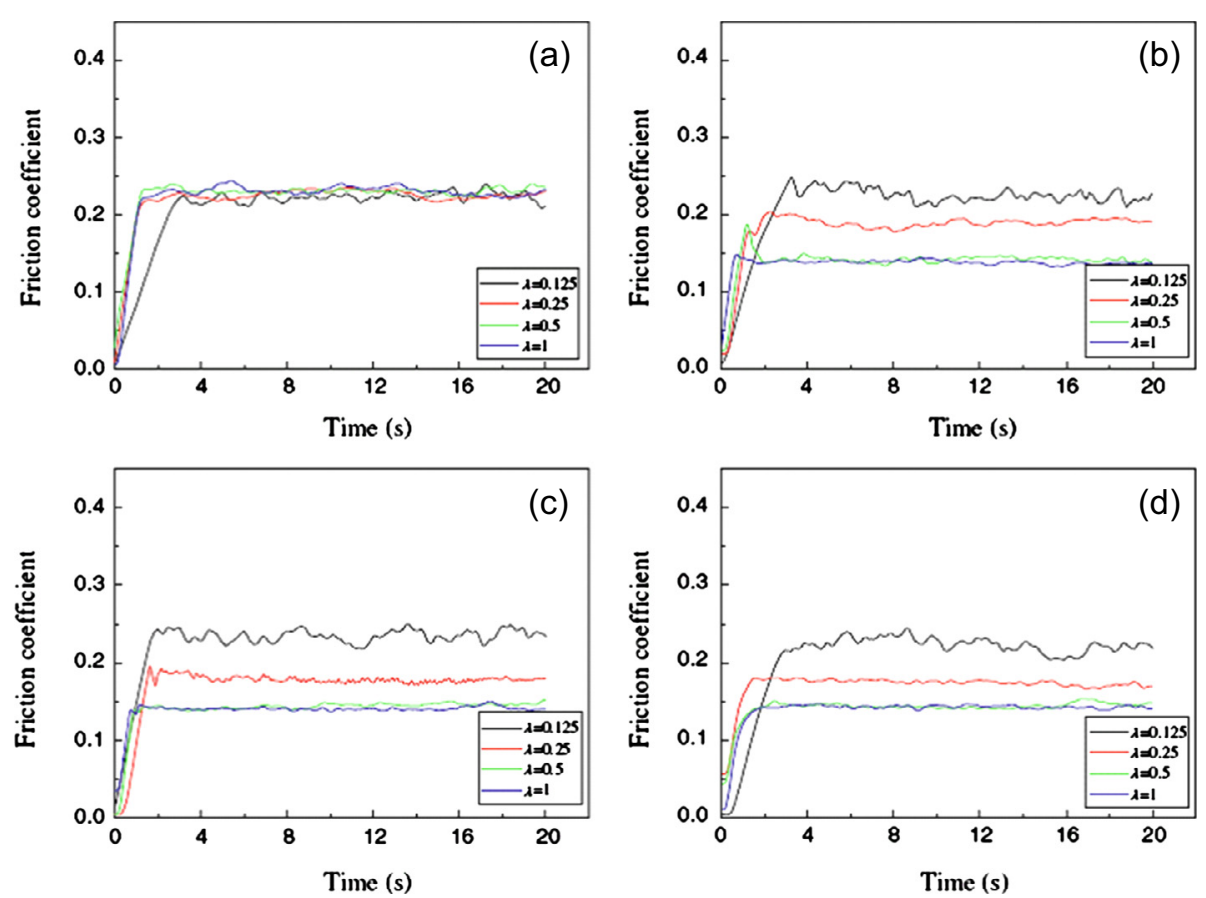

Figure 7. Effect of lubricated conditions on size effect: (a) without lubrication, (b) lubricated with soybean oil, (c) lubricated with castor oil, and (d) lubricated with petroleum jelly [28].

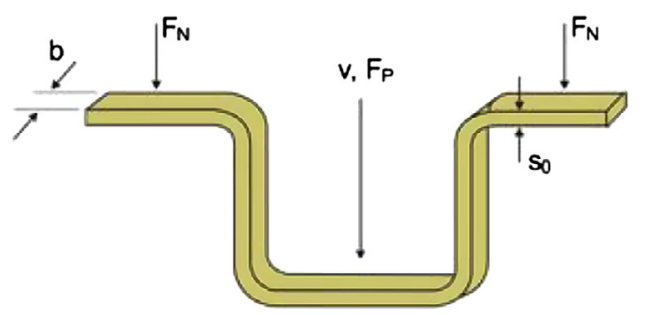

(a)

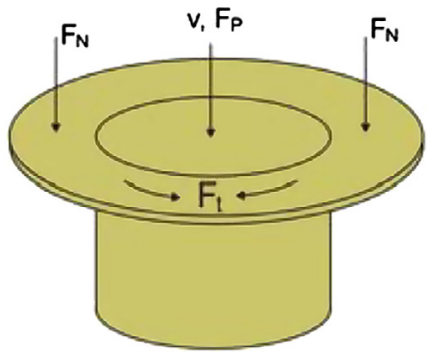

(b)

Figure 8. Principle of the friction test [29]: (a) strip drawing test, (b) deep drawing.

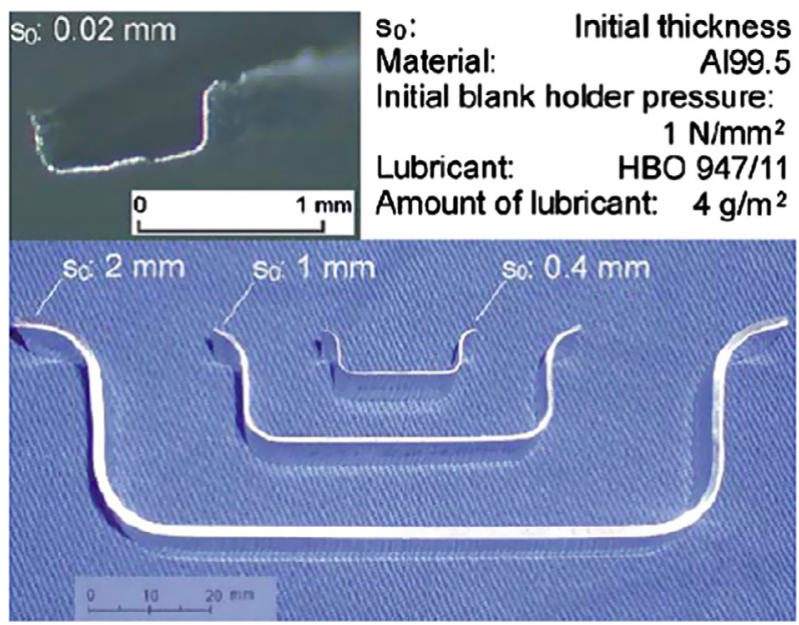

Figure 9. Drawn strips of different process dimensions [33].

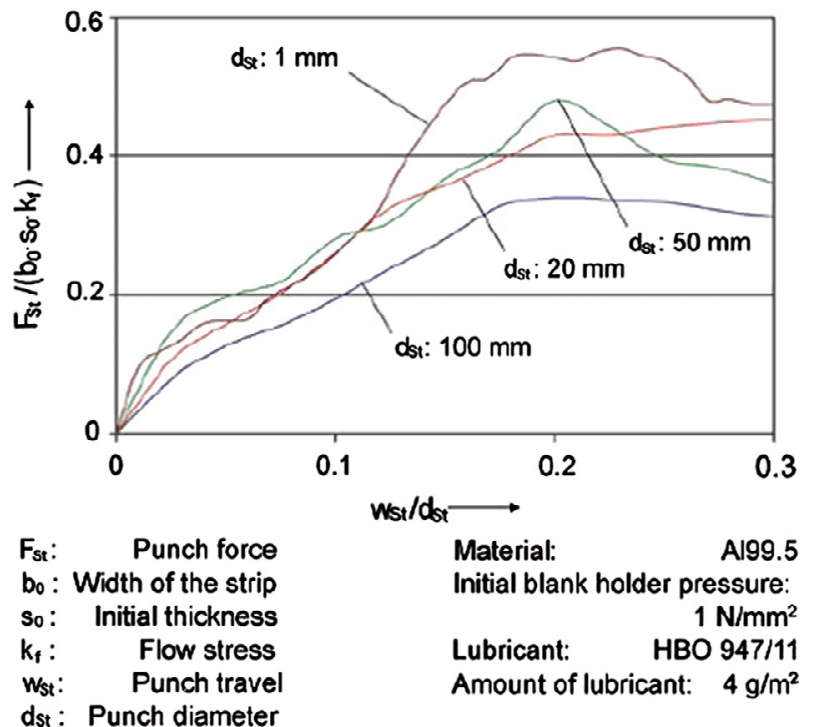

Figure 10. Normalized punch force vs. punch travel [33]. 


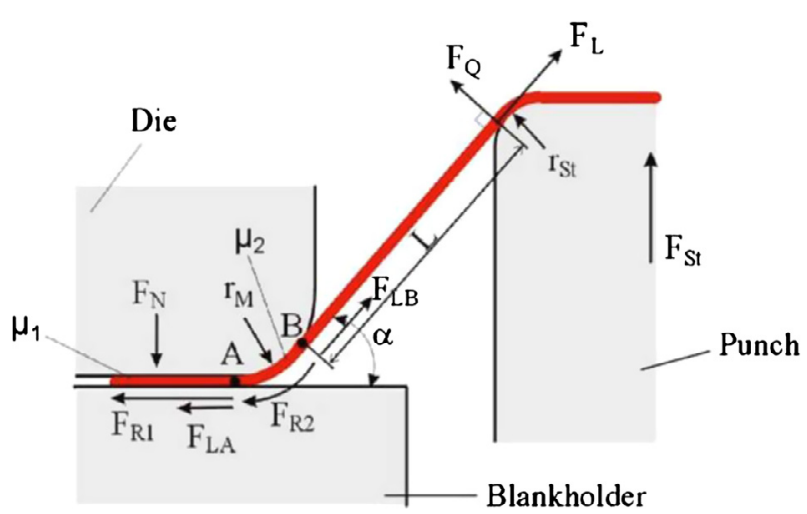

Figure 11. Analysis of the relationship of forces in strip drawing [11].

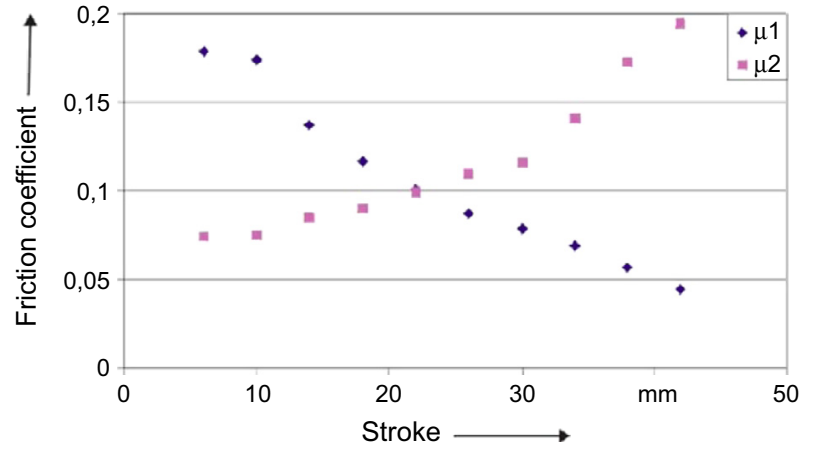

Figure 12. Distribution of $\mu_{1}$ and $\mu_{2}$ with lubricant applied at $2 \mathrm{~g} / \mathrm{mm}^{2}[11]$.

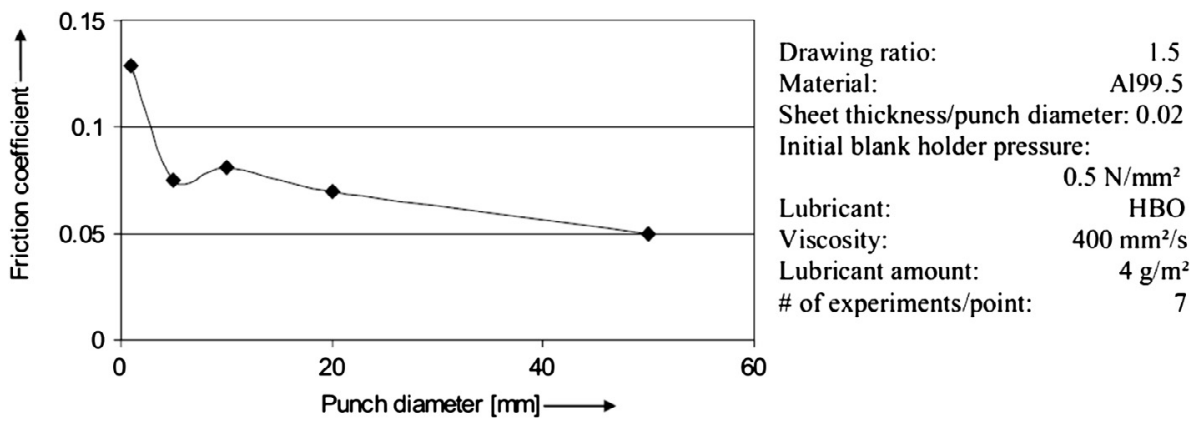

Figure 13. Size-dependent friction coefficient (determined by the use of Storoschew's equation) in mechanical deep drawing [38].

portion of the bending force and the bigger is the portion of the friction force, respectively. When changing the process dimensions, the share of friction force from the whole punch force differs: for a punch diameter of $1 \mathrm{~mm}$ it is the highest, and for a punch diameter of $100 \mathrm{~mm}$ it is the lowest [32-34].

To identify the friction coefficient based on the punch force vs. stroke curves achieved in experiments, a calculation model was developed. Based on the relation of forces shown in Figure 11, the following equations can be acquired:

$$
\begin{gathered}
F_{\mathrm{st}}=2\left(F_{Q} \cos \alpha+F_{L} \sin \alpha\right) \\
F_{Q}=\frac{M_{B(S)}}{L} \\
F_{L}=\left(2 F_{N} \mu_{1}+\frac{M_{B(A)}}{r_{M}+(s / 2)}\right) e^{\mu_{2} \alpha}+\frac{M_{B(B)}}{r_{M}+(s / 2)}
\end{gathered}
$$

where $F_{N}$ is the blank holder force; $\mu_{1}$ is the friction coefficient on the flange; $\mu_{2}$ is the friction coefficient on the die radius; $M_{B(A)}$ is the bending moment of the strip at point A; and $M_{B(B)}$ is the bending moment of the strip at point B $[11,32,35]$. The friction coefficient-travel curves were then calculated from the punch force (Fig. 12). The friction coefficient on the flange $\left(\mu_{1}\right)$ decreased from 0.179 to 0.045 , and the friction coefficient on the die radius $\left(\mu_{2}\right)$ increased from 0.074 to 0.195 . This stands for a new way for research in deep drawing tribology, especially in the field of size-effect research [11]. Using the scaled deep drawing with the same ratio of initial blank diameter $(D)$ /punch diameter $(d)$, a summary of the size-dependent friction coefficient in deep drawing is given in Figure 13. On average, they are 0.129 for a punch diameter of $1 \mathrm{~mm}, 0.075$ for a punch diameter of $5 \mathrm{~mm}$ and 0.081 for a punch diameter of $10 \mathrm{~mm}$, which shows that if the process dimension decreases, the friction increases. Moreover, the tribological size effects can affect the limiting drawing ratio [38].

Using a similar method, the importance of the surface topography of a sheet on tribological size effects was investigated by Wang et al. using smaller female die with a width of $0.6-1.4 \mathrm{~mm}$. The tribological size effects were observed clearly. With the surface of the specimens modified with the electrochemical polishing process, the punch force was reduced for bigger specimens, but the punch force was slightly increased when a small specimen was used, as shown in Figure 14. This means that the surface modification process leads to an increase of friction. The reason may be that the smooth surface is helpful for the escape of lubricant under high contact pressure $[12,36]$. These phenomena can be validated in another way. When the surface of a copper thin sheet was modified using ion beam irradiation equipment, many nano-crystals appeared on the surface as shown in Figure 15. This kind of surface with many nano-crystals is helpful for the storage of lubricant oil to reduce friction, which can be validated in strip drawing and micro deep drawing experiments [37]. 

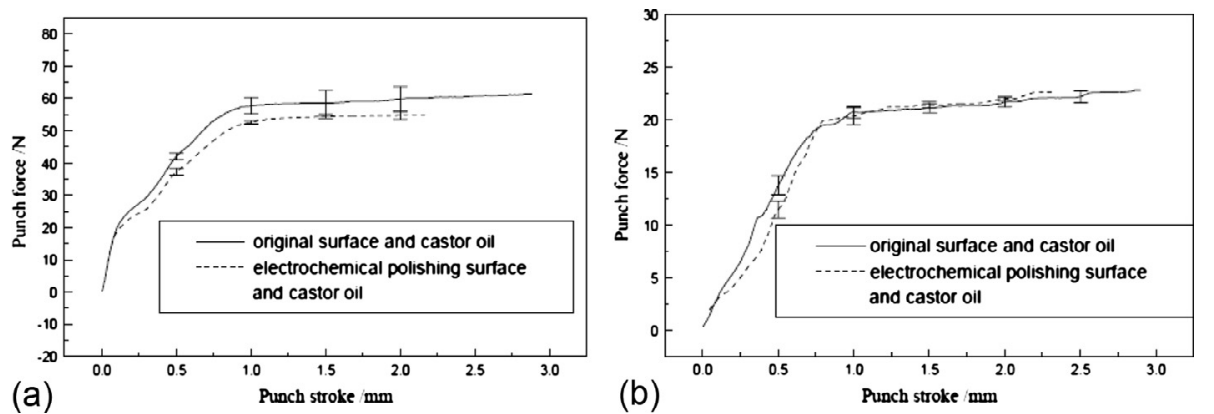

Figure 14. Curves of punch force-punch stroke for different surface quality [36]: (a) width of $4.5 \mathrm{~mm}$, (b) width of $1 \mathrm{~mm}$.

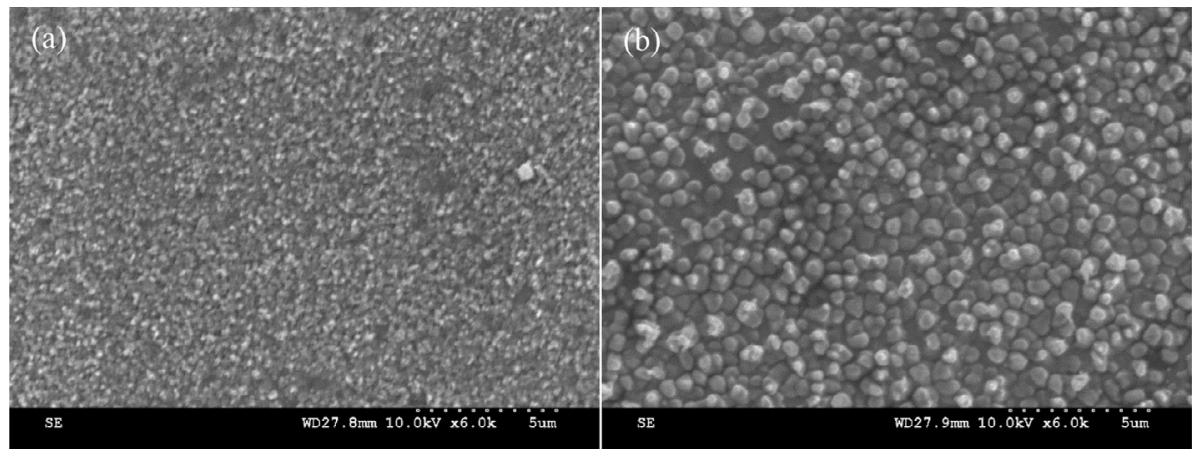

Figure 15. SEM photographs of the surface before and after modification [37]: (a) original surface, (b) surface modified with nano-crystals for $30 \mathrm{~min}$ at the mid-point.

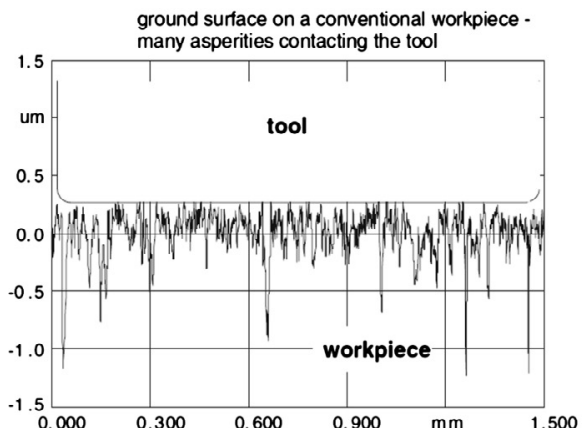

(a)

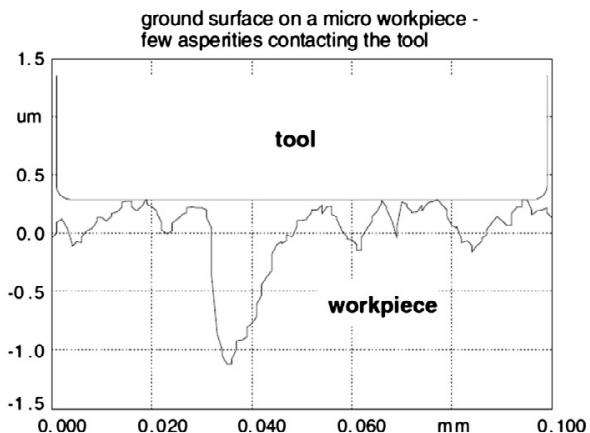

(b)

Figure 16. Asperities in contact on a workpiece in (a) conventional length scale and (b) on a micro part [41].

\subsection{Effect of surface characteristics on tribological behaviours in microforming}

Boundary and mixed lubrication conditions are predominant in metal forming processes. The apparent real contact area (RCA), which is mainly influenced by the topography of the tool and the workpiece, has a major impact on friction conditions [39]. In Engel's investigation [40], the effect of surface topography and its evolution were investigated by analysing the maximum of the closed-void area ratio and the closed-void volume for characterizing the tribological properties of the surface, even if there are only slight variations in the surface topography. When the surface features are approximately invariant with respect to the dimensions of the parts, the assessment areas have to be drastically reduced for surface roughness measurements of micro parts. Then, the evaluation area is no longer representative of the whole surface. The surface parameters are found to vary heavily depending on the specific measurement area that is selected by the user. On the other hand, as shown in Figure 16, concerning micro parts, only a small number of asperities are in contact with the tool. Hence, the properties and the behaviour of single asperities under load are much more important for the flattening of the surface and thus for the tribological behaviour of micro parts [41, 42].

To analyse the flattening behaviours of the asperities and the developing RCA, the surface is mapped three-dimensionally by an optical measuring device to determine the characteristic parameters as shown in Figure 17. Subsequent to the 


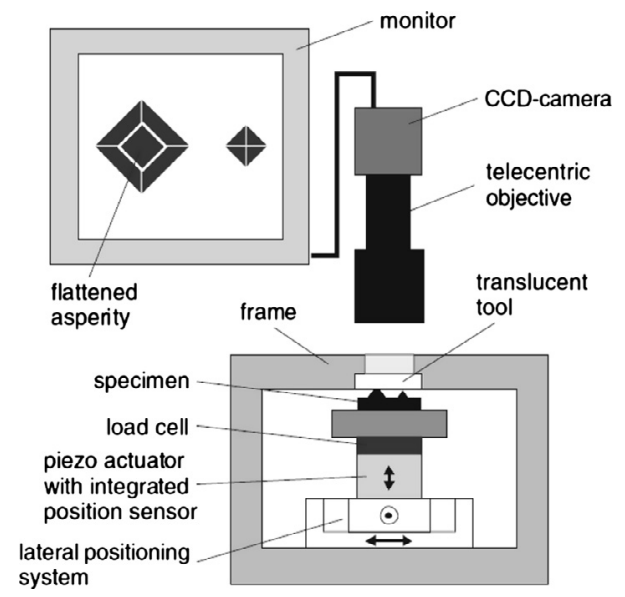

Figure 17. Experimental setup for the evaluation of the flattening behaviour and the formation of submicron cavities [41].

measurement of the surface, the surface data is imported to WinSAM (Surface Analysis Module for Windows), and the surface parameters then calculated. Using Pyramids with a base area of $120 \times 120 \mu \mathrm{m}$ and a height of $32 \mu \mathrm{m}$ as idealised asperities, the upsetting experiments are carried out with and without liquid lubricant for evaluating its influence on the flattening behaviour. For lubrication a mineral oil mixed with a dye for enhancing the contrast has been used [40-42]. As shown in Figure 18, in the case of the pyramidal specimen, there is no significant difference of topographic evolution between the lubricated and the non-lubricated case detectable because the lubricant is squeezed out of the contact area due to high flank angles of approx. $30^{\circ}$. In the case of the frustums of a pyramid, a considerable larger nominal contact area for the lubricated experiments is observable compared to the nonlubricated tests, indicating less resistance against lateral material flow, thus less friction in the contact area. Various topographic features such as dimples and valleys are visible in the contact area when lubricant is used in the upsetting deformation. In contrast to the lubricated case, there are hardly any pits or valleys observable when no mineral oil is used. With respect to the force-displacement curves, there is a slight tendency to reduced forces when lubricant is used [49]. The topography evolution and reduction in friction can be attributed to submicron lubrication effects within the nanotopography. When flattening idealised asperities with mineral oil based lubricant, a supporting effect of the lubricant has been observed which leads to smaller RCA compared to the non-lubricated case which would be in favour of low friction. This effect appears clearly when flattening model asperities with a flank angle of $5^{\circ}$. For idealised asperities with a flank angle of $28^{\circ}$, this effect occurs only at higher normal pressures [42-44].

These findings are supported by the calculation of the 3D surface parameters for the nominal contact area after complete flattening of the specimens. When frustums of a pyramid are upset with lubricant, there is a slight tendency towards higher values of the maximum ratio of the closed-void area and normalised closed-void volume of the flattened surface compared to the results of experiments where no influence on the friction conditions was detectable such as the flattening of the frustums of a pyramid without lubricant or a pyramid with lubricant. This indicates that a higher amount of smallest CLPs emerges during the lubricated flattening of frustums of a pyramid, resulting in lower friction [42].

\subsection{Wear of tools in microforming}

The tools used in microforming are characterised by small dimensions, and bear high contact pressure, which leads to wear or even invalidation occurring easily for micro-tools. An experimental and numerical investigation of the scale dependency was performed by Shimizu et al. to study the progressive adhesive behaviour of the work material under dry sliding friction in the micro deep drawing process. The transition of the maximum punch forces shows the different tendency between the scales. This tendency is strongly attributed to the adhered quantity of the work material on the drawing die radius. The variation of the tool surface with increasing number of the drawing tests is relatively lower for the micro scale, while the milli-scale shows the strong adhesion of the work materials on the forming tool surface. The analysis suggests that the relative short sliding length and small variation in surface roughness for the micro scale is responsible for the lower volume of wear of the work material. Thus, with the miniaturization of the process dimensions, the influence of the plowing by the adhered particles on the frictional properties seems to decrease [45]. On the other hand, investigations regarding the tool life show that the punching edge wears out quicker than the rest of the tool for the high contact pressure in a one-stroke micro blanking and deep drawing process used to produce micro-cups in high quantity with an outer diameter of $1 \mathrm{~mm}$. Furthermore, it is shown that the positioning of the tool has a high influence on the wear behaviour [46].

\section{Theory and models of the size effect of friction}

To explain the size effects of friction mentioned above, models, e.g. open and closed lubricant pockets, were developed based on the mechanical-rheological theory. Then, several kinds of functions were carried out to calculate the friction coefficient considering the scaling factor. On the other hand, a FC function was given after analysing the different contact pressure at different areas in a micro deep drawing process. These models and functions are helpful for understanding the mechanism of the size effects of friction, and furthermore for simulating the forming process in FEM.

\subsection{Open and closed pockets models and application in FE simulation}

In microforming when a kind of liquid lubricant was applied, the high increase in friction can be explained using the mechanical-rheological model or the model of open and closed lubricant pockets developed by Engel et al. When a forming load is applied to a lubricated workpiece surface, 


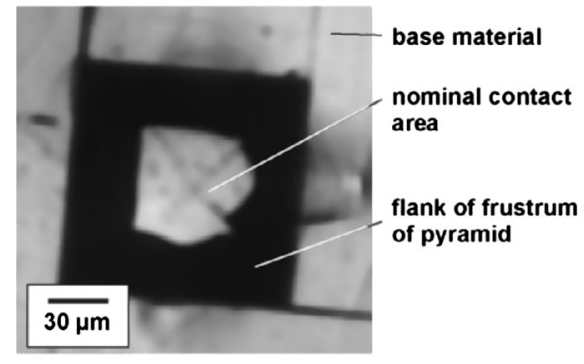

(a)

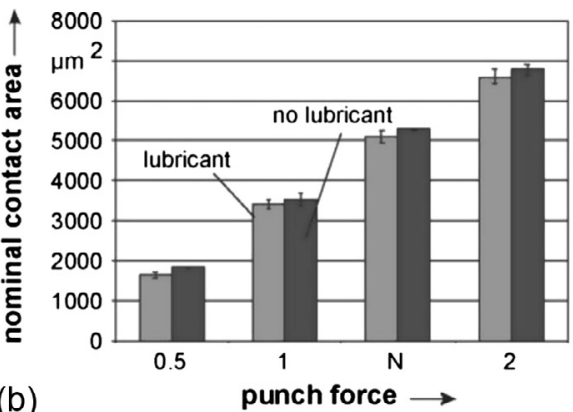

(b)

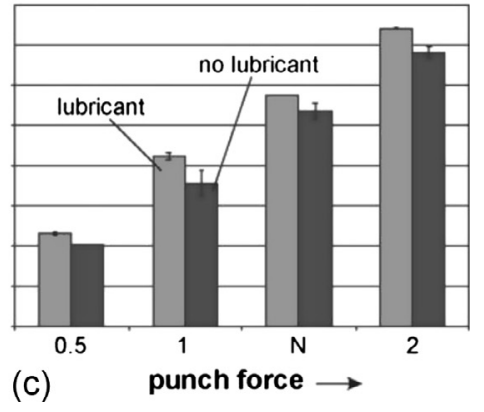

(c)

Figure 18. (a) View through translucent tool; (b) nominal contact area for pyramid; (c) nominal contact area for frustum of pyramid [42].

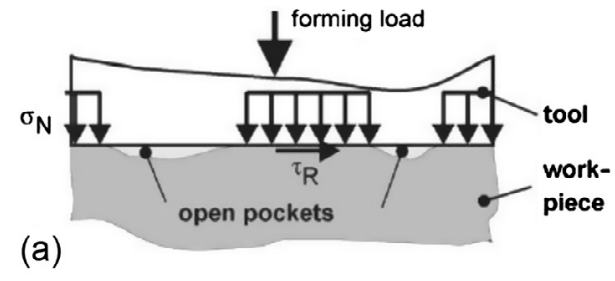

(b)

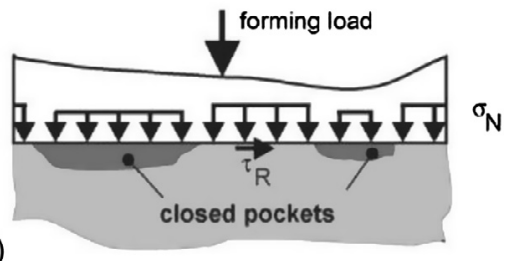

Figure 19. Open (a) and closed (b) lubricant pockets [5].

the asperities (roughness peaks) start to deform plastically, thus increasing the pressure of the lubricant, which is trapped in the intervening roughness valleys or squeezed out. Roughness valleys that have a connection to the edge of the surface and cannot retain the lubricant, are called open lubricant pockets (OPLs). With increasing normal pressure, the lubricant escapes and is not able to support or transmit the forming load (Fig. 19a). The forming load acts only on the asperities which results in a higher contact stress, a higher degree of surface flattening and thus, a higher fraction of RCA and higher friction. Closed lubricant pockets (CLPs), on the contrary, do not have a connection to the edge of the surface. The lubricant becomes trapped in those pockets and is pressurized during forming. The developing hydrostatic pressure will take a part of the external load, thus reducing the normal pressure on the asperities, which results in lower friction (Fig. 19b) $[5,10,21]$. Applying this model to the DCE test outlined above, there must be a scaling effect on the ratio of open to closed lubricant pockets, as shown in Figure 20. It is obvious that there is a region of constant width (denoted by $x$ ) where the open lubricant pockets become effective. This assumption is further supported by the roughness measurements. The ratio of open to closed lubricant pockets does not only increase with a decreasing specimen size, but also with the decreasing initial specimen height when the diameter is held constant [20].

In Engel's investigation [10] to describe the size effect of friction in a mathematical way, a theoretical approach was

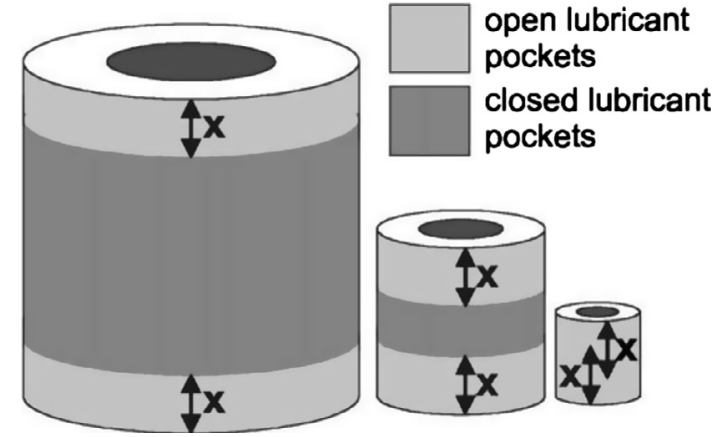

Figure 20. Effect of miniaturization on areas with open and closed lubricant pockets [5].

suggested based on the general friction law developed by Wanheim and Bay, and the RCA of a scaled-down specimen was introduced into the model to describe the size effect, which could be determined by $3 \mathrm{D}$-surface profilometry measurement as shown in Figure 21. The results are good agreement with the analysis shown above. The geometrical effect can be expressed in terms of the scaling factor $\lambda$. In the case of a circular cylinder, e.g. for the situation given in the DCE test, the relationship between the RCA ratio $\alpha_{R C}$, closed lubricant pockets (CLPs) ratio $\alpha_{\mathrm{CL}}$, and open lubricant pockets (OLPs) ratio $\alpha_{\mathrm{OP}}$ can be obtained,

$$
\frac{\alpha_{\mathrm{OP}}}{1-\alpha_{\mathrm{RC}}}=\frac{\alpha_{\mathrm{OP}}}{\alpha_{\mathrm{CL}}+\alpha_{\mathrm{OP}}}=\frac{1}{\lambda}
$$

Equation (6) is not only valid for the DCE test but also for all cases in which the nominal contact area is surrounded by two independent rims. In the case of only one rim (all kinds of upsetting, extrusion, etc.), it becomes:

$$
\frac{\alpha_{\mathrm{OP}}}{1-\alpha_{\mathrm{RC}}}=\frac{\alpha_{\mathrm{OP}}}{\alpha_{\mathrm{CL}}+\alpha_{\mathrm{OP}}}=\frac{2 \lambda-1}{\lambda^{2}}
$$

Equations (6) and (7) are both indicated in Figure 22, which shows that the geometrical effect should be considered in the range of $1<\lambda<10$, and be negligible for high values of $\lambda$ (say $\lambda>10$, i.e. for "macro").

The normal stress is responsible for flattening the asperities. The corresponding function of $\alpha_{\mathrm{RC}}$ can be obtained under the given mean flank angle of the asperities. It should be noted 

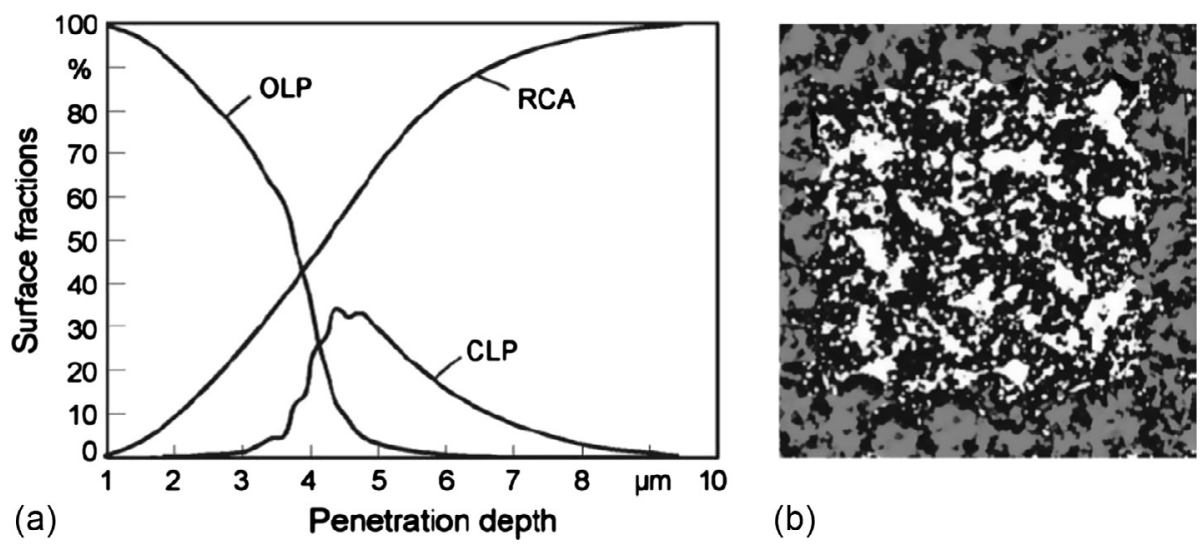

(b)

Figure 21. 3D-surface analysis. Surface fractions as function of vertical penetration for a measurement area of $2.4 \mathrm{~mm} \times 2.4 \mathrm{~mm}$; (a) exemplary presentation, (b) distribution of surface fractions (RCA, black; CLPs, white; OLPs, grey) at a penetration depth of $4 \mu \mathrm{m}$ for a cut-out of $1 \mathrm{~mm} \times 1 \mathrm{~mm}[10]$.

that the relationships are valid for the conditions that the normal pressure is entirely propped up by the RCA, which certainly is true for dry friction. In the case of lubrication and pre-supposing the existence of CLPs, some valleys among peaks, especially those valleys located internally, can retain lubricant to form enclosed lubricant (Fig. 23). It can be assumed that the stress acting on the asperities is reduced by the effect of hydrostatics pressure developing in the CLPs $[10,47]$,

$$
\sigma_{n}=\sigma_{n}^{0}+\left(1-\frac{1-\alpha_{\mathrm{RC}}}{\lambda}\right) p
$$

where $\sigma_{n}$ is the normal pressure acting on the total surface under lubrication conditions, $\sigma_{n}^{0}$ is the stress which under non-lubricated conditions would yield the same $\alpha_{\mathrm{RC}}$, and $p$ is the fraction of stress which is taken over by hydrostatic pressure via the CLPs. Based on the foregoing discussion, it is reasonable to assume that friction factor $f$ is proportional to $p(\lambda)$ being responsible for building up the pressure inside the CLPs. Since this effect must be restricted to the portion of the surface where only RCA and CLP are present, then it can be written as:

$$
f=f_{\max }-\frac{f_{\max }-f^{*}}{p^{*}} p\left(1-\frac{1}{\lambda}\right)
$$

For $\lambda \rightarrow \infty$, the friction factor will approach its minimum, value which can be obtained via the Wanheim/Bay model. The maximum value is simply adapted to the experimental observation yielding $f_{\max } \alpha_{\mathrm{RCmax}}=m_{\max }=0.4$ for $\lambda=1$. This means that the size effect of friction is qualitatively explained by the invariance of surface topography to scaling.

Based on the Wanheim/Bay general friction model, Peng et al. developed a new uniform friction model which could be established for multi-scale considering the size/scale factor $\lambda$,

$$
\tau=f \varphi(p, \lambda) k(\lambda \geq 1)
$$

It is found that the model can reveal the mechanism of frictional size effects. The influence of a size/scale factor is greater in micro/meso scale $(\lambda<10)$ than that in conventional scale $(\lambda>10)$, which is the reason why size effects should be considered in a micro/meso scale forming process, while it could be ignored in a macro scale process [47].

The models shown above do not give the equation of friction coefficient directly, and the properties of the lubricant were not discussed. Based on the assumption of open and closed lubricant pockets as shown in Figure 24, the relationship between the fraction of CLPs, OLPs, and RCA can be obtained by Wang et al. using the scaling factor $\lambda$. According to the general Wanheim/Bay model, the curves between the RCA and normal pressure are close to a linear relationship under dry friction conditions when the friction factor and flank angle are the same. Based on the Coulomb law, the coefficient of friction can be calculated considering the interface contact state in micro scale:

$$
\mu_{\text {mic }}=\mu_{0}\left[1-\frac{p_{l}}{p_{m}}\left(1-\alpha_{\mathrm{RC}}\right)\left(1-\frac{1}{\lambda}\right)^{2}\right]
$$

where pressure $P_{l}$ is induced by the compression of lubricant volume trapped in the CLPs. Then, $P_{l}$ can be calculated by the lubricant tangent bulk modulus $K$ and reduction in volume enclosed in the CLPs.

$$
K=-V \frac{\mathrm{d} P_{l}}{\mathrm{~d} V}
$$

The model can be used to realize the mechanism of frictional size effects: also, the effect of the lubricant properties were analysed. When a kind of lubricant with larger tangent bulk modulus is applied, the fraction of RCA is smaller because of the larger pressure $P_{l}$. Then, the friction coefficient is smaller with the same scaling factor. This means that the properties of the lubricant have an obvious effect on the scaling effect of friction. The developed model is validated by the cylindrical upsetting of cylinders of different dimensions through calculating their shape parameters [48].

To analyse the tribological behaviour in microforming with inhomogeneous mechanical property materials, the Tabor friction model was modified by introducing the friction factor 


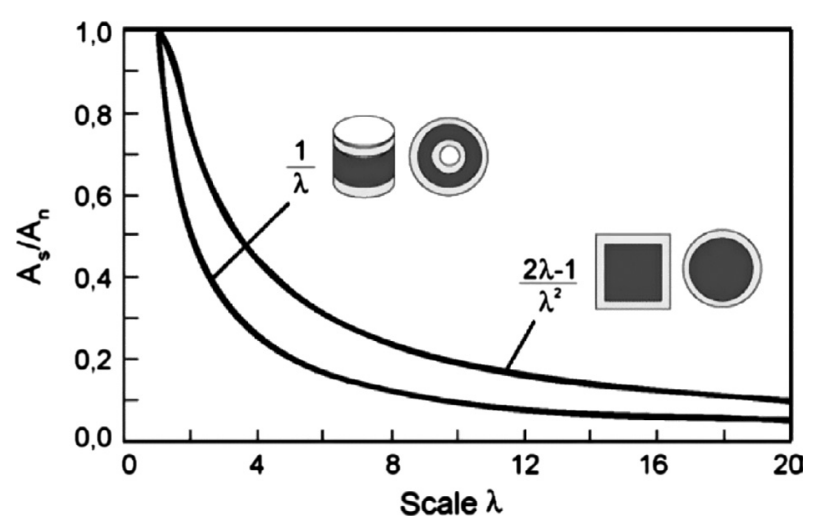

Figure 22. Effect of the scaling factor on the OLP-fraction [10].

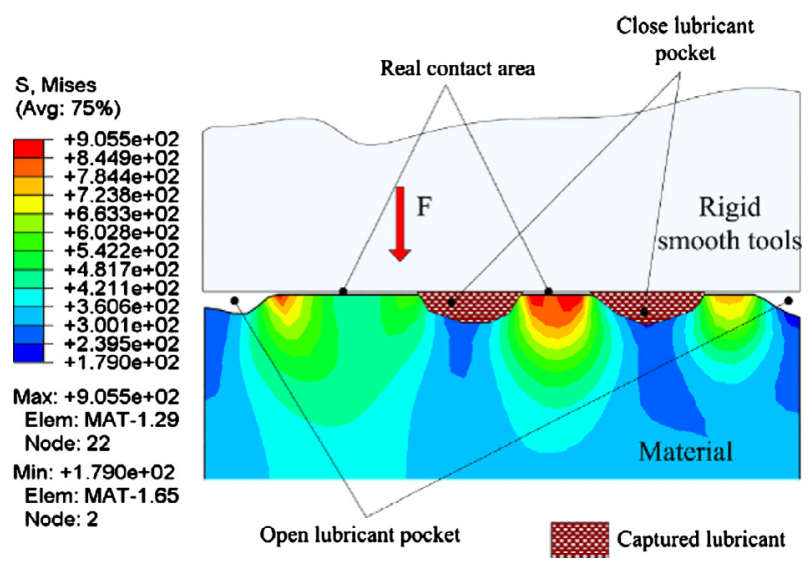

Figure 23. 2-D sketch of OLPs, RCAs, and CLPs [45].

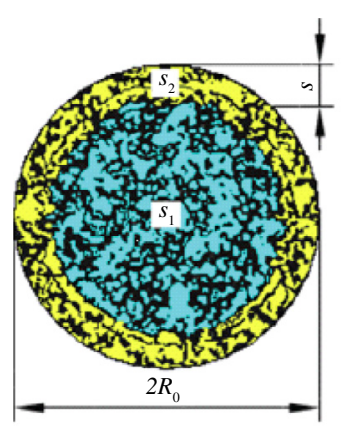

(a)

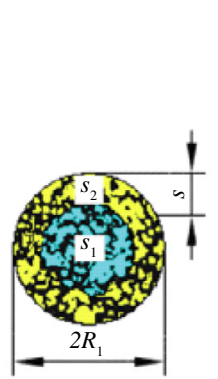

(b)
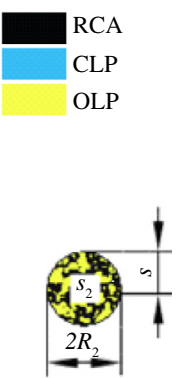

(c)
Figure 24. Distribution of surface fractions in cylinder upsetting [48].

established by Wanheim, and a new equation for the friction coefficient was obtained:

$$
\mu=\frac{f_{\alpha}}{\sqrt{3\left(1-f^{2} \alpha^{2}\right)}+\sqrt{3} \alpha^{n / 2}}
$$

where $f$ is the friction factor, and $\alpha$ is the contact area ratio, which can be obtained from:

$$
\alpha=\tanh \left(C_{\alpha} \frac{P}{\sigma_{u}}\right)
$$

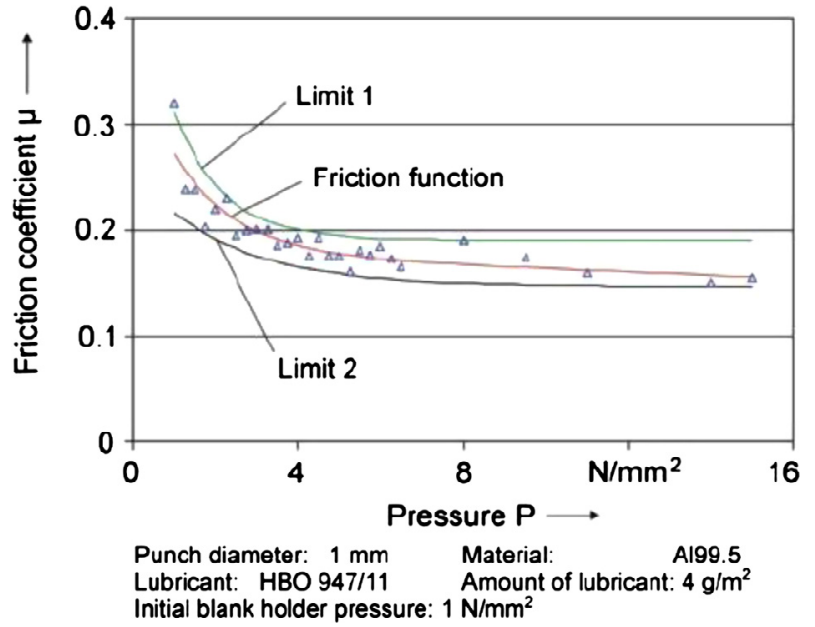

Figure 25. Friction coefficient calculated from the experimental punch force vs. travel and friction function [33].

Based on the multi-region model including the grainboundary and grain orientation, the micro-uniaxial compression process was simulated to study the size effect considering dry friction. It was found that the grain-boundary has little effect on the dry friction behaviour. The mechanical properties of individual grains either in the contact area or in the noncontact area have a significant influence on the friction behaviour. With decrease of the specimen's size, the average friction coefficient did not vary significantly, but the value of the friction coefficient of each random grain orientation distribution becomes more dispersive [49].

\subsection{FC function and application in FE simulation}

Based on the experiments and obtained punch force vs. stroke curves of strip drawing experiments using thin sheet shown in Section 2.1, Vollertsen et al. described the trend through some mathematic functions, e.g. equation (15) [30, $31,33]$. The coefficients $C_{1}-C_{5}$ have no physical meaning, and can be determined with an optimisation program developed by BIAS and ZeTem (University Bremen):

$$
\begin{aligned}
\mu= & C_{1}+C_{2} \times \exp \left(-P \times C_{4}\right)+C_{3} \\
& \times \exp \left(-P \times C_{5}\right)
\end{aligned}
$$

where $\mu$ is the friction coefficent, and $P$ is the contact pressure [33]. The friction coefficient at different strokes can be calculated from the experimental punch force vs. travel. Due to the different contact pressure at different strokes, these points locate in a narrow band in the diagram of friction coefficient over contact pressure. Figure 25 shows the friction coefficient points of the experiment with a punch diameter of $1 \mathrm{~mm}$. This band shows a trend of dependence of the friction coefficient on the contact pressure [33, 35].

A graphical display of these friction functions is shown in Figure 26. A difference with a factor of about 2 between the friction functions with punch diameters of 1 and $100 \mathrm{~mm}$ is described, which illustrates a tribological size effect within the range of the investigation. The results of FE-simulation 


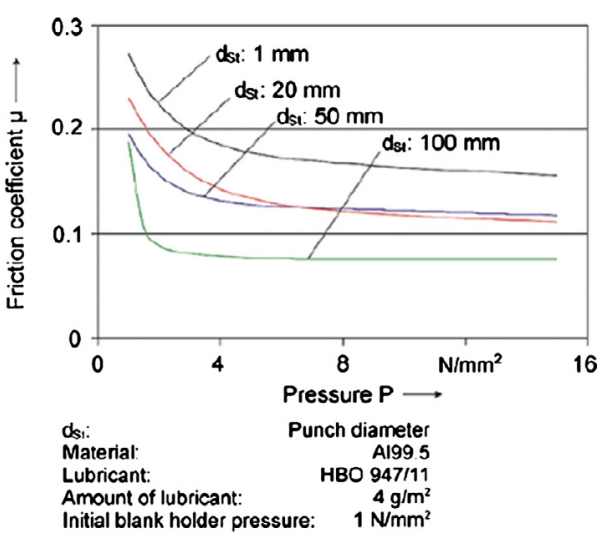

Figure 26. Friction functions for different process dimensions $[33,34]$.
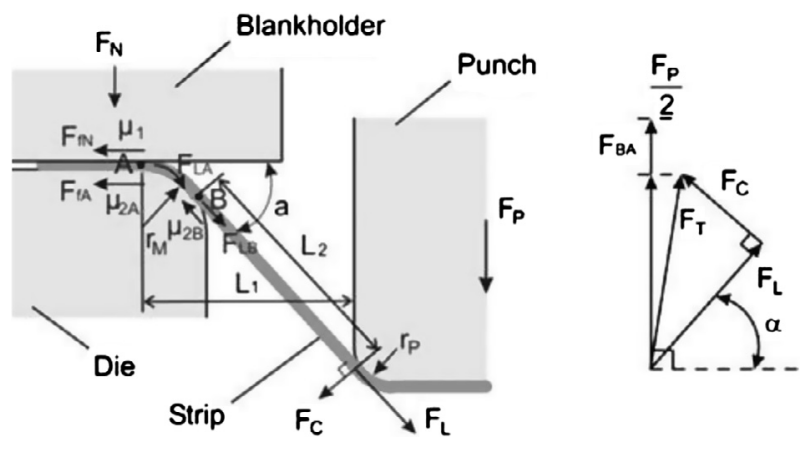

Figure 27. Analysis of forces in strip drawing [35].

show that the contact between the workpiece and the die at the radius of the die concentrates on two zones, and each contact zone has a length of about $2 \%$ of the punch diameter, i.e. $2 \mathrm{~mm}$ for the punch diameter of $100 \mathrm{~mm}$ and only $0.02 \mathrm{~mm}$ for the punch diameter of $1 \mathrm{~mm}$, which might be the possible reason for the size effects of friction. These friction functions can be integrated into the FEM-simulation program Abaqus. This makes it possible to simulate a sheet metal forming process with consideration of tribological size effects. However, the simulated curve using the friction function has a big difference from the experimental curve. The reason might be the assumption in the calculation model that the normal pressure at the radius is uniform [29, 33, 34].

To optimize the previous analytical model with respect to the distribution of the contact pressure at the drawing radius, Vollertsen et al. developed a new analytical model considering the non-uniform distribution of contact pressure between the workpiece and the tools. One of assumptions is that the contact zone between the blank and the die at the drawing radius divides into two zones if the length of the contact zone is greater than the thickness of the blank, and the two contact zones have the same length, equal to half of the blank thickness. The forces involved in the strip drawing process are shown in Figure 27. The friction force between the blank and the die at point $\mathrm{A}$ is given by:

$$
F_{f A}=\left(F_{N}+F_{B A}\right) \times \mu_{2 A}\left(P_{2 A}\right)
$$

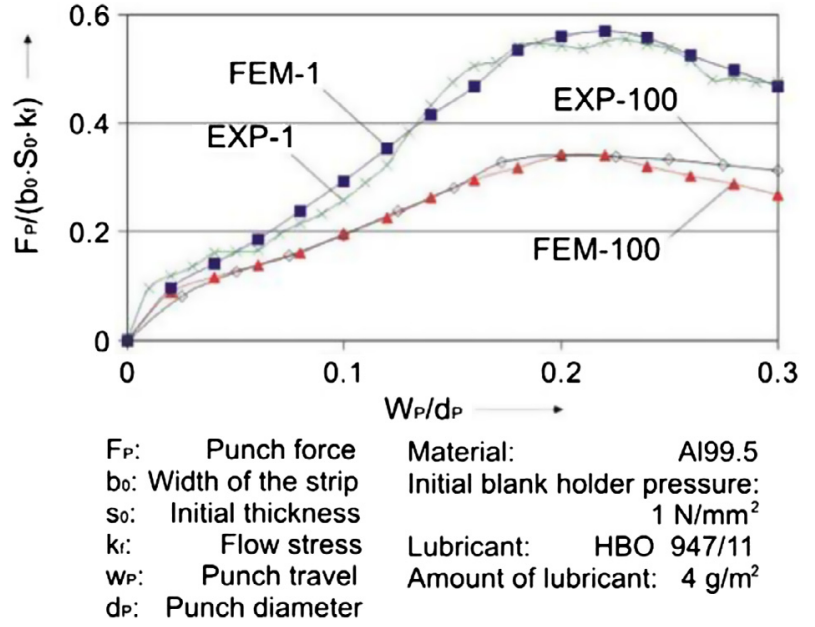

Figure 28. Comparison of experimental and simulated punch force vs. punch travel curves using the new friction functions [35].

According to the assumption, the whole strip drawing process is considered as two phases. Phase 1 has only one high impact contact between the blank and the die at the drawing radius, which can be determined from:

$$
F_{2 A}=\frac{F_{N}+F_{B A}+F_{B P}+2 F_{L A} \times \sin (0.5 \alpha)}{b_{0} \times L_{C}}
$$

Phase 2 has two high impact contacts, and the normal contact pressures at two points are determined by:

$$
\begin{gathered}
F_{2 A}=\frac{F_{N}+F_{B A}+2 F_{L A} \times \sin \left(0.5 \alpha_{s}\right)}{b_{0} \times L_{C A}} \\
F_{2 B}=\frac{F_{B P}+\left(F_{L B}+F_{B B}+F_{L A}\right) \times \sin \left(\alpha-\alpha_{s}\right)}{b_{0} \times L_{C B}}
\end{gathered}
$$

Using the same form of mathematical description, the new corresponding function coefficients can be calculated. Applying the new friction functions into the FE-simulation model, the simulated results are in better agreement with the experimental results for the two punch diameters of 1 and $100 \mathrm{~mm}$, as shown in Figure 28 [35]. Although the modified model is better than before, there are too many parameters in the function, which make it difficult in application.

\subsection{Surface roughness model in FE simulation}

For considering the evolution of the surface structure during the contact phase, the micro-mechanical approach is necessary. As shown in Figure 29, when the profile is pushed down with a flat punch, the material of the peak flows into the valleys. The surface topography changes under the applied loads within a forming process. By insertion of a fictive intermediate layer between the tool and an ideal roughness workpiece, a new concept for the description of the surface structure is presented. The parameters used for the characterisation of technical surfaces are: centre line average height $R_{a}$, depth of roughness 


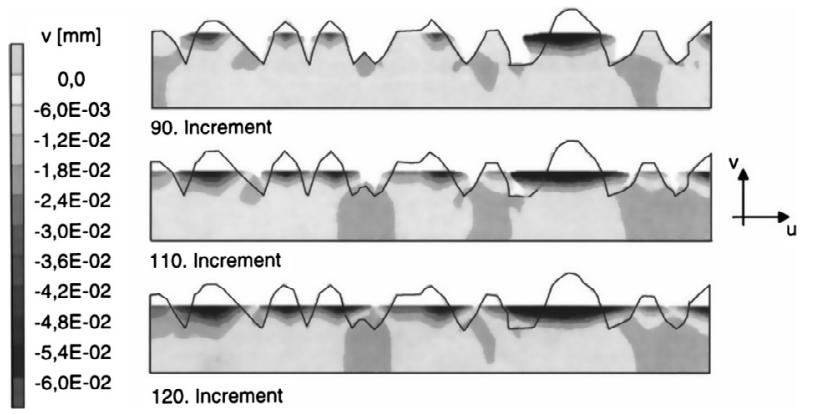

Figure 29. Development of the vertical displacement [50].

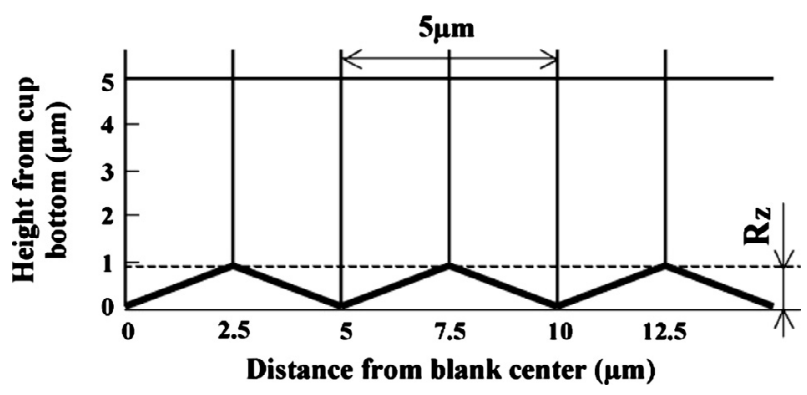

Figure 30. Example of a surface roughness model [53].

$R_{z}$, and maximum profile height $R_{y}$; enabling the FEsimulation of real sheet metal parts to be carried out [50]. To simplify the analytical procedure, an equivalent asperity, which is a statistical representation of the surface, was used by Qin et al. to determine the deformation of the surface. The validation suggested that the model was sufficiently accurate for use in the prediction of the surface characteristics of material that has been subjected to interfacial pressure [51].

In micro deep drawing, Manabe et al. used a cyclic concavo-convex configuration on the surface elements of the blank and all of the tools in the FE model, considering the surface asperities as shown in Figure 30. The surface roughness used in the model was the average of the values measured in the experiments. The simulation was validated in the micro deep drawing of $500 \mu \mathrm{m}$ diameter of cup using $20 \mu \mathrm{m}$ ultrathin SUS304 foil. The results show that the roughness of the tool and the blank surfaces considerably affects the product accuracy and quality of the micro-scale product. For achieving high surface quality of formed micro parts, it is estimated that the micro-die and tool surface should be finished and polished to less than $0.078 \mu \mathrm{m}$ roughness at least for deep drawing at sub-millimeter scale [52, 53]. In ring compression, the tool surface is modelled with a sinusoidal (elliptical) profile and zero friction, as shown in Figure 31. A relationship $f(m)=f(a, t)$ was introduced, where amplitude $a$ and period $t$ describe an equivalent elliptical profile, which can be determined by a surface profilometer. The relationship has been determined only for the dry condition, but can lead the way on incorporating the presence of a lubricant and the effect of varying the workpiece material characteristics in future research [54]. For microforming application, a depth-dependent stress-strain relation was derived from the indentation size effect model and this stress-strain relationship was used in a simulation to

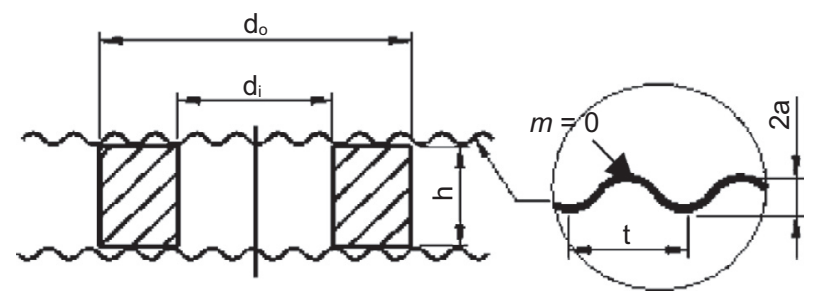

Figure 31. Geometric model of the tool surface using an elliptical profile [54].

show the effect of strain gradient on friction behaviour in microforming at different surface roughness levels. The current model showed satisfactory agreement when it was compared with experimental tribometer results for a polished and ground surface even without the artificial implementation of a friction coefficient [55].

\section{Lubrication methods in microforming}

For the existence of frictional size effects during the miniaturization, some new lubrication methods should be introduced in microforming. Surface modification of the tools and the specimen, e.g. DLC film, micro structured or textured surface, have been validated to be very suitable for microforming in reducing the friction coefficient and the size effects of friction.

\subsection{Surface coating}

The excellent tribological properties of diamond-like carbon (DLC) film have been gaining increasingly more attention. The most important feature is that it can eliminate the size effect of friction in microforming, and it can also protect the micro-die in respect of its wear resistance and anti-adhesion characteristics. The application of DLC coated tools is also becoming much wider in microforming.

Wang et al. carried out the evaluation of the tribological properties of DCL film in micro strip drawing, and the results showed that the friction coefficient was lower, even better than that of castor oil when a polished specimen of $1 \mathrm{~mm}$ in width was applied. The interesting thing was that its tribological behaviour were not affected by the change width of the specimen. After hundreds of tests, there was no cracking or chipping at the surface of the DLC film, which meant that the DLC film had the ability to bear larger strain/stress $[12,56]$. Doped DLC film, e.g. Si-DLC film, showed high potential in tribocharacters such as friction and anti-pick-up under the heavy conditions of high ironing reduction and no active lubrication in the strip-ironing test. This indicates that Si-DLC has the possibility of application in dry forming with a high pressure, a surface expansion and a long sliding distance [57].

With different deposition parameters, DLC film with different properties can be obtained. For example, the evaluation of damage due to wear indicates a strong wear-proof property but delamination is easier with the condition of $1.0 \mathrm{kV}$ in the bending process with thin foil. Contrarily, the DLC film with the condition of $3.0 \mathrm{kV}$ shows strong adhesion to the substrate 


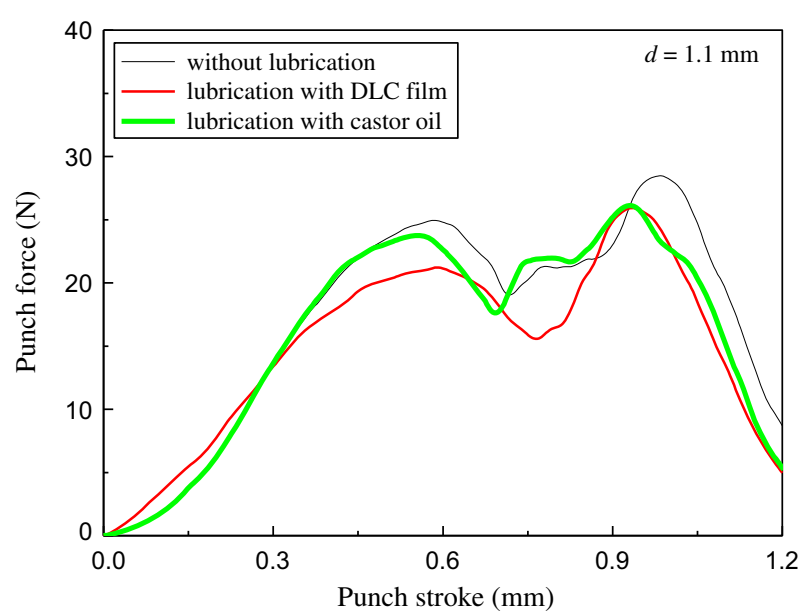

Figure 32. Punch stroke-punch force curves [62].

but it is easier to wear. By changing the deposition parameters, Yang et al. produced a DLC film with a gradient in properties with both wear resistance and lower friction, which could be appropriate for metal forming at sub-millimeter size [58, 59]. In another case, the bias voltage was alternatively controlled between zero and high voltage, whereupon nano-laminated DLC film was deposited. The results indicate that both Young's modulus and hardness increase monotonically with decrease of the sub-layer thickness. Dry bending tests showed that a coating with sub-layer thickness, e.g. $10 \mathrm{~nm}$, had excellent tribological properties which could improve the coated tool life, and decrease the friction $[60,61]$.

Based on the analysis of friction in micro deep drawing, the blank holder and female die, both manufactured with tool steel JIS-SKD11, were deposited with DLC film using the PBII\&D method. Wang et al. performed the micro deep drawing process using DLC-coated tools, and high limiting drawing ratio (LDR) was increased from 1.8 for without lubrication to 2.1 for DLC surface modified tools. The drawing punch stroke-force curves for a drawing punch diameter of $1.1 \mathrm{~mm}$ are shown in Figure 32, using heat-treated T2 copper thin sheet. The punch load for lubrication with DLC film was reduced by approximately $15 \%$. This means that the friction coefficient between the DLC film and sheet was much lower than that for other lubrication conditions. In micro deep drawing with Au foil, its tribological properties are even better than that of a PE [63].

The durability and wear of DLC film in micro sheet forming was investigated by Vollertsen et al. using a blanking and deep drawing tool combination with a maximum stroke rate of 200 parts per minute. Experiments with copper foil of $0.05 \mathrm{~mm}$ thickness were performed to produce cylindrical micro-cups with a diameter of $1.0 \mathrm{~mm}$. The punch and die of $0.9 \mathrm{~mm}$ and $1.06 \mathrm{~mm}$ diameter, respectively, are both made of stainless steel. The results show that an uncoated tool has a longer life than a coated tool, which was not expected. The further investigation found that there were many scattered carbides and pores with different size. The coated carbides can break out during a mechanical stress state as existing in micro deep drawing, which may damage the DLC film and cause the delamination. Therefore, it is important to choose tool material with homogeneous microstructure $[64,65]$. This founding can

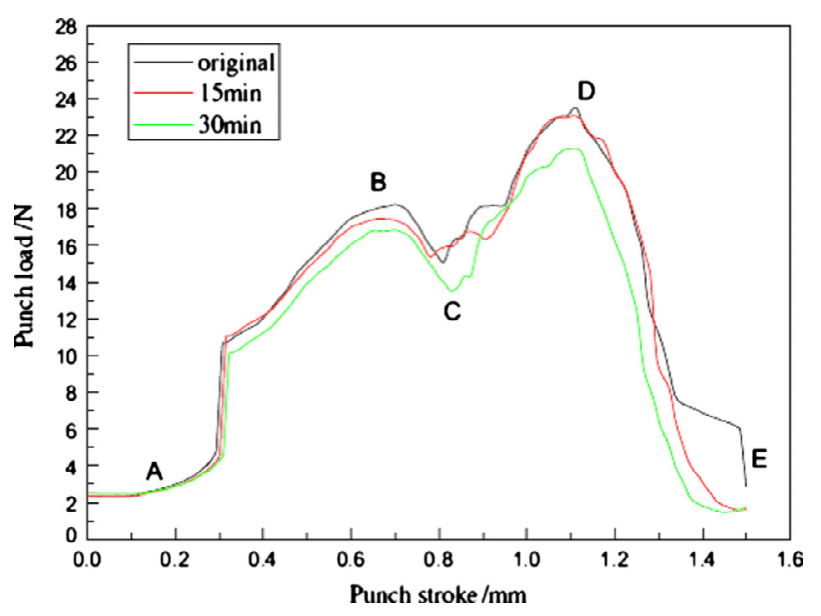

Figure 33. Curves of punch load vs. stroke [37].

be validated by tests using $\mathrm{WC}$ as tool material. Even after 50,000 strokes with $\mathrm{Cu}$-alloy sheet, no delamination and damage took place on any surface of the punches and dies, together with no scratches on the surface of the drawn cups [66].

Also, the validity of using high strength/low friction die coating was investigated by $\mathrm{Cao}$ et al. in micro-extrusion with pure aluminium at room temperature. The typical extrusion indicates that the maximum extrusion force for the DLCSpatter coated die was the lowest $(25 \mathrm{kN})$, which was lower than $28 \mathrm{kN}$ for DLC-Arc coated die, $30 \mathrm{kN}$ for CrN coated die, $29 \mathrm{kN}$ for TiN coated die, and $32 \mathrm{kN}$ for uncoated die. These results show that the DLC-Spatter coating produces the least friction and therefore has the lowest extrusion force. Similarly, Si-DLC film shows the lowest extrusion force and the greatest pin-length extruded [21, 67, 68].

Some other surface coatings were applied to expand the lubrication techniques the in microforming. The Octadecyltrichlorosilane (OTS) self-assembled monolayer was chosen as a potential lubricant because it sticks to Si wafer die and can be applied to surface with uniform thickness of several nanometer thick. It was found that OTS self-assembled monolayer coated Si wafer offers substantially lower friction and lower adhesion than bare Si wafer. Micro channel wafer die was coated with OTS self-assembled monolayer and channel forming operation with $1 \mu \mathrm{m}$ thick copper foil was carried out. It was shown that OTS self-assembled monolayer coating reduces the friction and adhesion substantially, and successfully improved the formability of the thin foil channel forming [69].

\subsection{Micro structured surface}

In metal forming, the tools are exposed to extremely high loads, and the failure mechanism is mostly initiated on the tool surface. Surface texture has been proven already in some industrial application to increase tool life [70-72]. In the macro industry, some samples have successfully realized reductions in friction coefficient from 0.12 to 0.10 compared to a lapped smooth surface without texturing [73-76]. In strip-drawing tests using dies with grooves in large area coverage $(\approx 25 \%)$, significant effects were noted on the friction between the dies 

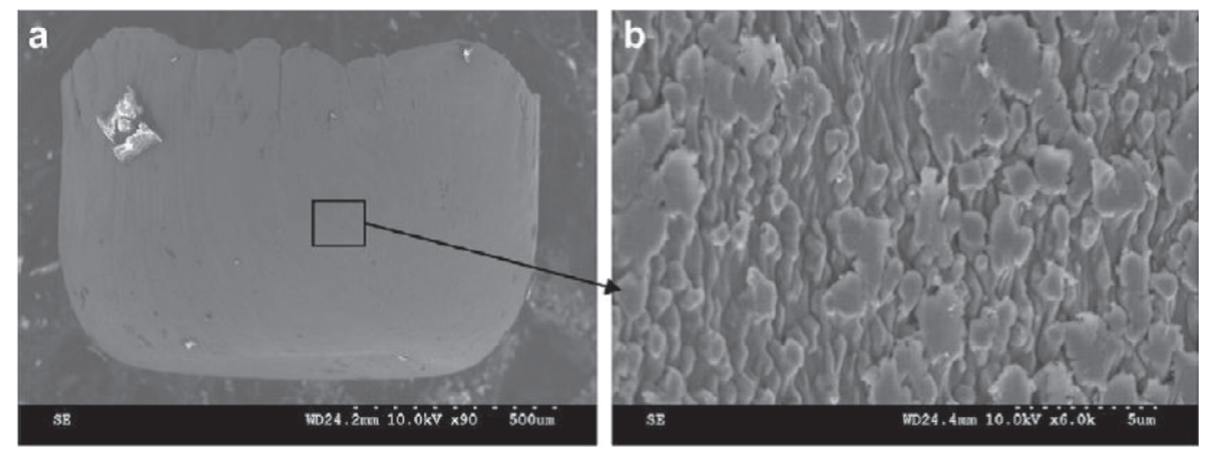

Figure 34. Surface topography of a micro-cup modified specimen (30 min) (a) micro-cup, (b) surface topography [37].

and the strip, which were reflected in the drawing force. The performance was strongly influenced by the relative orientation between the grooves and the drawing direction [77]. In ring upsetting and rod extrusion processes, it was found that a turned surface was more effective than other textures, in holding greater quantities of lubricant and thereby reducing friction in ring compression, but the resultant surface roughness was high. For extrusion, in contrast with ring upsetting, shot-blasted surfaces offered the lowest friction and the turned surfaces produced the lowest surface roughness [78]. In facemilling experiments of aluminium alloy, it was shown that a nano/micro-textured surface promoted anti-adhesive effects at the tool-chip interface [79]. In micro-systems, the effectiveness of controlling the frictional force at the micro-scale using well structured surface micro-grooves was demonstrated. This is attributed to the reduced apparent area of contact which can be beneficial in reducing the contribution of adhesion due to meniscus formation at the contact junctions [80].

Based on the validation of the influence and significance of micro structures on friction and tribological behaviour in macro forming, a novel approach was performed in locally modulating the surface of microforming dies and moulds with adapted micro structures. A strip drawing test applied to various different micro machined surfaces reveals the influence on the coefficient of friction and therefore on the tribological performance. In general, it was found that micro structured surfaces with an average roughness Sa between 50 and $600 \mathrm{~nm}$ provide less friction than polished surfaces. This can be explained by the increased adhesive forces of smooth surfaces. On the other hand, very rough surfaces (macro structures) also increase the friction forces, due to the abrasive effect of material peaks. It is assumed that the ideal surface with the lowest friction can be found at an average roughness Sa of $200-400 \mathrm{~nm}$. For the impact of line pitch on the coefficient of friction, the polynomial regression is less significant, but still some trends can be recognized. A beneficial micro topography can be achieved for microforming by carefully choosing micro milling or micro grinding processes [13].

Besides the surface modification of tools, the workpiece surface topography is also an important factor controlling the mechanisms of lubrication in metal forming processes [81]. In micro-deep drawing, Wang et al. performed the surface modification of copper foil using the ion beam irradiation method. Many nano-crystals appeared on the surface of the copper foil. The strip drawing experiments showed that the friction coefficient decreased from 0.11 for the original specimen to 0.095 for the modified specimen, for 15 min irradiation. Then, surface modified copper foil was applied in the micro-deep drawing of $1.1 \mathrm{~mm}$ diameter specimens. As shown in Figure 33, the punch load for the modified surface is lower than that for the original specimen. With the increase of irradiation time, the punch load clearly decreases. To realize the mechanism of reduction of punch load, the surface of formed micro-cups were observed as shown in Figure 34. It was noted that many roughness valleys are left on the surface after deep drawing, which can trap more lubricant oil. This means that the nano-crystals at the copper surface are helpful for the storage of lubricant oil, and bearing higher contact pressure in micro deep drawing, and in turn reducing the friction [37].

\section{Conclusions and outlook}

Friction is of greatest importance for process feasibility and process quality in microforming, even more critically than that in macro forming. However, the size effects of friction are complex and sensitive to the contact parameters and surface topography of interfaces, which may not be well understood. This study intends to provide an overview of experimental researches, models and functions on the size effects of friction, and also on the methods to reduce friction which are suitable for microforming. The collected and analysed information from this review can be summarized as below:

1. Numerous experimental investigations on size effects of friction have been performed using DCE and upsetting deformation etc. for micro bulk forming, and the strip drawing test for micro sheet forming. It was found that friction coefficient/factor increases clearly during the miniaturization in microforming. Also, the evolution of the surface topography of the workpiece at the interface was analysed both with and without lubricant.

2. Analysing models, e.g. open and closed lubricant pockets, were developed based on the mechanical-rheological theory. Then, several kinds of functions based on this model were carried explored out to calculate the friction coefficient considering the scaling factor. On the other hand, a FC function was developed for the micro deep drawing process to consider the different contact pressure at different areas of the tools. The models and 
functions are helpful for understanding the mechanism of size effects of friction, and furthermore for simulating the microforming process with FEM.

3. Some new lubrication methods have been introduced in microforming. Surface modification of tools and specimens, e.g. DLC film, micro structured or textured surfaces, were validated to be very suitable for microforming in reducing the friction coefficient and the size effects of friction.

Although many investigations on size effects of friction have been performed in the last 10 years, the existing frictional theories and analytical methods are far from sufficient for friction analysis in microforming $[82,83]$. There are many works that should be done in the future, which include:

1. A method for the evaluation of the friction coefficient with higher accuracy should be developed and it should consider real conditions during microforming. The experiment should be designed and conducted to obtain friction coefficient by directly considering the characteristics of microforming. New measurement and sensor technology may be helpful for such a work. For example, a new two-axis force sensor maybe used to measure both, the vertical load (used to calculate the contact pressure) and lateral force (for calculating the friction) at the same time. After the sensor is embedded into a forming-die, the contact force and friction could be monitored on-line, which should provide a better solution to the process monitoring and control. As described above, the friction coefficient was determined largely through iteration methods with FE analysis. FE analysis of microforming itself is more or less a largely simplified method. Modelling with polycrystalline structures of metallic materials considering grain size, crystal orientation, shape and location of grains, based on the crystal plastic theory, should lead to more accurate simulations.

2. The real state of the interfacial contact between tools and the workpiece should be considered. Some simple assumptions have been used before, e.g. topography of workpiece surface is simplified into an isosceles triangle, was introduced in the calculation. It would be better to consider real topography in investigation of tribology in the future research. Based on the measurement of surface topography, the contour of surface roughness may be depicted with a statistical parameter surface, which could then be transferred directly to the FE software to form an analysis model. With the help of FE software, deformation behaviours of surface topography and with presence of different lubricants should be considered in the analysing of tribological behaviours.

3. More methods should be explored for reduction of friction in microforming. The surface modification of tools is one of the most important methods in microforming. Although the DLC film with gradient properties and nano-laminated DLC film are very suitable for microforming, surface modification with other doped elements, e.g. $\mathrm{Si}$, is also a useful way to obtain lower friction and higher adhesion strength, and can also be used for a high contact pressure and temperature condition. Comparing to expensive surface-modification methods such as PVD or CVD, a laser micro-texturing of tool-surfaces may be a cheaper way to enable reduction of friction. For micro-forming tools with very small die-cavities, surface modification is difficult to achieve with currently existing techniques. The future work should be conducted to address this development needs.

Acknowledgements. The authors gratefully acknowledge the financial support of the National Science Foundation of China (No. 51375113). The first author would also like to thank Prof. Yi Qin, Director of Centre for Precision Manufacturing, the University of Strathclyde, for providing beneficial discussion on microforming research and Prof. Frank Travis for carefully checking the manuscript.

\section{References}

1. M.W. Fu, W.L. Chan, A review on the state-of-the-art microforming technologies, The International Journal of Advanced Manufacturing Technology 67 (2013) 2411-2437.

2. Y. Qin, A. Brockett, Y. Ma, A. Razali, J. Zhao, C. Harrison, W. Pan, X. Dai, D. Loziak, Micro-manufacturing: research, technology outcomes and development issues, The International Journal of Advanced Manufacturing Technology 47 (2010) 821-837.

3. M. Geiger, M. Kleiner, R. Eckstein, N. Tiesler, U. Engel, Microforming, CIRP Annals - Manufacturing Technology 50 (2001) 445-462.

4. J. Jeswiet, M. Geiger, U. Engel, M. Kleiner, M. Schikorra, J. Duflou, R. Neugebauer, P. Bariani, S. Bruschi, Metal forming progress since 2000, CIRP Journal of Manufacturing Science and Technology 1 (2008) 2-17.

5. U. Engel, R. Eckstein, Microforming-from basic research to its realization, Journal of Materials Processing Technology 125-126 (2002) 35-44.

6. F. Vollertsen, Categories of size effects, Production Engineering Research and Development 2 (2008) 377-383.

7. Y. Qin, Microforming and miniature manufacturing systemsdevelopment needs and perspectives, Journal of Materials Processing Technology 177 (2006) 8-18.

8. C.J. Wang, D.B. Shan, J. Zhou, B. Guo, L.N. Sun, Size effects of the cavity dimensions on the microforming ability during coining process, Journal of Materials Processing Technology 187-188 (2007) 256-259.

9. C. Wang, C.J. Wang, B. Guo, D.B. Shan, G. Huang, Size effect on flow stress in uniaxial compression of pure nickel cylinders with a few grains across thickness, Material Letters 106 (2013) 294-296.

10. U. Engel, Tribology in microforming, Wear 260 (2006) 265-273.

11. F. Vollertsen, Z. Hu, H. Schulze Niehoff, C. Theiler, State of the art in microforming and investigations into micro deep drawing, Journal of Materials Processing Technology 151 (2004) 70-79.

12. C.J. Wang, B. Guo, D.B. Shan, X.M. Bai, Tribological behaviors of DLC film deposited on female die used in strip drawing, Journal of Materials Processing Technology 213 (2013) 323-329. 
13. E. Brinksmeier, O. Riemer, S. Twardy, Tribological behavior of micro structured surfaces for microforming tools, International Journal of Machine Tools and Manufacture 50 (2010) 425-430.

14. A.R. Razali, Y. Qin, A review on micro-manufacturing, microforming and their key issues, Procedia Engineering 53 (2013) 665-672.

15. A. Messner, U. Engel, R. Kals, F. Vollertsen, Size effect in the FE-simulation of microforming processes, Journal of Materials Processing Technology 45 (1994) 371-376.

16. W.L. Chan, M.W. Fu, J. Lu, The size effect on micro deformation behaviour in micro-scale plastic deformation, Materials and Design 32 (2011) 198-206.

17. N. Tiesler, U. Engel, M. Geiger, Forming of microparts-effects of miniaturization on friction, Proceeding of the Sixth International Conference on Technology of Plasticity, Nuremberg, Germany, September 19-24, 1999, pp. 889-894.

18. M. Geiger, A. Messner, U. Engel, Production of microparts size effects in bulk metal forming, Production Engineering 4 (1997) 55-58.

19. U. Engel, A. Messner, N. Tiesler, Cold forging of microparts effect of miniaturization on friction, Proceedings of the First ESAFORM Conference on Materials Forming, Sophia Antipolis, France, 1998, pp. 77-80.

20. N. Tiesler, U. Engel, Microforming-effects of miniaturization, Proceedings of the 8th International Conference on Metal Forming, Rotterdam, Holland, 2000, pp. 355-360.

21. N. Tielser, Microforming-size effects in friction and their influence on extrusion processes, Wire 52 (2002) 34-38.

22. N. Krishnan, J. Cao, K. Dohda, Study of the size effects on friction conditions in microextrusion-Part I: Microextrusion experiments and analysis, Journal of Manufacturing Science and Engineering 129 (2007) 669-676.

23. L.F. Mori, N. Krishnan, J. Cao, H.D. Espinosa, Study of the size effects and friction conditions in microextrusion-Part II: Size effect in dynamic friction for brass-steel pairs, Journal of Manufacturing Science and Engineering 129 (2007) 677-689.

24. W.L. Chan, M.W. Fu, B. Yang, Study of size effect in microextrusion process of pure copper, Materials and Design 32 (2011) 3772-3782.

25. F. Gong, B. Guo, C.J. Wang, D.B. Shan, Size effect on friction of C3602 in cylinder compression, Tribology Transactions 53 (2010) 244-248.

26. B. Guo, F. Gong, C.J. Wang, D.B. Shan, Flow stress and tribology size effects in scaled down cylinder compression, Transactions of Nonferrous Metals Society of China 19 (2009) s516-s520.

27. P.S. Nielsen, N.A. Paldan, M. Calaon, N. Bay, Scale effects in metal-forming of friction and lubrication, Proceeding of the Institution of Mechanical Engineers, Part J: Journal of Engineering Tribology 225 (2011) 924-931.

28. B. Guo, F. Gong, C.J. Wang, D.B. Shan, Size effect on friction in scaled down strip drawing, Journal of Materials Science 45 (2010) 4067-4072.

29. Z. Hu, F. Vollertsen, Modelling of friction with respect to size effects, International Journal of Material Forming 1 (2008) 1231-1234.

30. Z. Hu, F. Vollertsen, Friction test for deep drawing with respect to size-effects, Proceeding of the 1 st International Conference on New Forming Technology, Harbin, China, September 6-9, 2004, pp. 153-158.
31. F. Vollertsen, H. Schulzer Niehoff, Z. Hu, State of the art in microforming, International Journal of Machine Tools and Manufacturing 46 (2006) 1172-1179.

32. Z. Hu, F. Vollertsen, A new frictions test method, Journal for Technology of Plasticity 29 (2004) 1-10.

33. F. Vollertsen, Z. Hu, Tribological size effects in sheet metal forming measured by a strip drawing test, CIRP Annals Manufacturing Technology 55 (2006) 291-294.

34. F. Vollertsen, D. Biermann, H.N. Hansen, I.S. Jawahir, K. Kuzman, Size effects in manufacturing of metallic components, CIRP Annals - Manufacturing Technology 58 (2009) 566-587.

35. F. Vollertsen, Z. Hu, Determination of size-dependent friction functions in sheet metal forming with respect to the distribution of the contact pressure, Production Engineering Research and Development 2 (2008) 345-350.

36. C.J. Wang, B. Guo, D.B. Shan, Y. Yao, F. Gong, Size effect of tribology behaviour in micro U-deep drawing with T2 copper foil, Steel Research International 81 (2010) 1177-1180.

37. C.J. Wang, B. Guo, D.B. Shan, J. Xu, H. Zhuang, Effect of nano-crystals at surfaces induced by ion beam irradiation on the tribological behaviour in microforming, Vacuum 89 (2013) 267-270.

38. F. Vollertsen, Z. Hu, On the drawing limit in micro deep drawing, Journal for Technology of Plasticity 32 (2007) 1-12.

39. R.S. Eriksen, S. Weidel, H.N. Hansen, Tribological influence of tool surface roughness within microforming, International Journal of Material Forming 3 (2010) 419-422.

40. M. Pfestorf, U. Engel, M. Geiger, Three-dimensional characterization of surfaces for sheet metal forming, Wear 216 (1998) 244-250.

41. S. Weidel, U. Engel, Surface characterisation in forming processes by functional 3D parameters, The International Journal of Advanced Manufacturing Technology 33 (2007) 130-136.

42. S. Weidel, U. Engel, Characterisation of the flattening behaviour of modelled asperities, Wear 266 (2009) 596-599.

43. S. Weidel, U. Engel, Impact of liquid lubricant on the flattening behaviour of single asperities, November 12, 2007, http:// www.4m-org.org

44. S. Weidel, U. Engel, M. Merklein, M. Geiger, Basic investigation on boundary lubrication in metal forming processes by in situ observation of the real contact area, Production Engineering Research and Development 4 (2010) 107-114.

45. T. Shimizu, Y. Murashige, S. Iwaoka, M. Yang, K. Manabe, Scale dependence of adhesion behavior under dry friction in progressive micro-deep drawing, Journal of Solid Mechanics and Materials Engineering 7 (2013) 251-263.

46. H. Flosky, F. Vollertsen, Wear behavior in a combined micro blanking and deep drawing process, CIRP Annals - Manufacturing Technology 63 (2014) 281-284.

47. L.F. Peng, X.M. Lai, H.J. Lee, J.H. Song, J. Ni, Friction behavior modeling and analysis in micro/meso scale metal forming process, Materials \& Design 31 (2010) 1953-1961.

48. C.J. Wang, B. Guo, D.B. Shan, M.M. Zhang, X.M. Bai, Tribological behaviors in microforming considering microscopically trapped lubricant at contact interface, The International Journal of Advanced Manufacturing Technology 71 (2014) 2083-2090.

49. W. Zheng, G.C. Wang, G.Q. Zhao, D.B. Wei, Z.Y. Jiang, Modelling and analysis of dry friction in microforming of metals, Tribology International 57 (2013) 202-209. 
50. E. Doege, C. Kaminsky, A. Bagaviev, A new concept for the description of surface friction phenomena, Journal of Materials Processing Technology 94 (1999) 189-192.

51. X.S. Chen, Y. Qin, R. Balendra, Development of a statistical parameter-based surface model for the simulation of variation of surface roughness with contact pressure, Journal of Materials Processing Technology 145 (2004) 247-255.

52. K. Manabe, H. Koyama, H. Nouka, M. Yang, K. Ito, Finite element analysis of micro cup drawing process using tool and blank models with surface roughness, Proceeding of the Eighth International Conference on Technology of Plasticity, Verona, Italy, October 9-13, 2005.

53. K. Manabe, T. Shimizu, H. Koyama, M. Yang, K. Ito, Validation of FE simulation based on surface roughness model in micro-deep drawing, Journal of Materials Processing Technology 204 (2008) 89-93.

54. J. Jeon, A.N. Bramley, A friction model for microforming, The International Journal of Advanced Manufacturing Technology 33 (2007) 125-129.

55. M. Taureza, X. Song, S. Castagne, Depth-dependent stressstrain relation for friction prediction, International Journal of Mechanical Science 86 (2014) 46-53.

56. C.J. Wang, C.J. Wang, B. Guo, D.B. Shan, Effects of tribological behaviors of DLC film on micro-deep drawing processes, Transactions of Nonferrous Metals Society of China 24 (2014) 2877-2882.

57. K. Kitamura, T. Ymamoto, Y. Tsuchiya, K. Dohda, Application of DLC-coating to metal forming die, Proceeding of International Conference on Tribology in Manufacture Processes, Yokohama, Japan, September 24-26, 2007, pp. 169-174.

58. K. Fujimoto, M. Yang, M. Hotta, H. Koyama, S. Nakano, K. Morikawa, J. Cairney, Fabrication of dies in micro-scale for micro-sheet metal forming, Journal of Materials Processing Technology 177 (2006) 639-643.

59. M. Yang, K. Manabe, K. Ito, Micro press forming and assembling of micro parts in a progressive die, Journal of Mechanical Science and Technology 21 (2007) 1338-1343.

60. T. Aizawa, E. Iwamura, K. Itoh, Nano-lamination in amorphous carbon for tailored coating in micro-dry stamping of AISI-304 stainless steel sheets, Surface and Coatings Technology 203 (2008) 794-798.

61. T. Aizawa, K. Itoh, E. Iwamura, Nano-laminated DLC film for dry micro-stamping, Steel Research International 81 (2010) 1169-1172.

62. F. Gong, B. Guo, C.J. Wang, D.B. Shan, Micro deep drawing of micro cups by using DLC film coated blank holders and dies, Diamond and Related Materials 20 (2011) 196-200.

63. C.J. Wang, B. Guo, D.B. Shan, X.M. Bai, Experimental research on micro-deep drawing processes of pure gold thin sheet using DLC-coated female die, The International Journal of Advanced Manufacturing Technology 67 (2013) 2477-2487.

64. Z.Y. Hu, A. Schubnov, F. Vollertsen, Tribological behaviour of DLC-films and their application in micro deep drawing, Journal of Materials Processing Technology 122 (2012) 647-652.

65. H. Flosky, F. Vollertsen, Wear behavior of a DLC-coated blanking and deep drawing tool combination, Key Engineering Materials 549 (2013) 511-517.

66. H. Morita, T. Aizawa, N. Yoshida, S. Kurozumi, Dry transfer stamping by nano-laminated DLC-coated tool, Proceeding of 10th International Conference on Technology of Plasticity, Aachen, Germany, September 25-30, 2011, pp. 1103-1108.

67. N. Takatsuji, K. Dohda, T. Makino, T. Yoshimura, Friction behavior in aluminium micro-extrusion, International Conference on Tribology in Manufacture Processes, Yokohama, Japan, September 24-26, 2007, pp. 157-162.

68. N. Krishnan, J. Cao, K. Dohda, Microforming: study of friction conditions and the impact of low friction/high strength die coatings on the extrusion of microparts, Proceeding of ASME International Mechanical Engineering Conference and Exposition, Orlando, USA, November 2005, pp. 1-10.

69. S.W. Baek, S.I. Oh, S.H. Rhim, Lubrication for microforming of ultra thin metal foil, CIRP Annals - Manufacturing Technology 55 (2006) 295-298.

70. K. Wagner, A. Putz, U. Engel, Improvement of tool life in cold forging by locally optimized surfaces, Journal of Materials Processing Technology 177 (2006) 206-209.

71. K. Wagner, R. Völkl, U. Engel, Tool life enhancement in cold forging by locally optimized surfaces, Journal of Materials Processing Technology 201 (2008) 2-8.

72. A.A.G. Bruzzone, H.L. Costa, P.M. Lonardo, D.A. Lucca, Advances in engineered surfaces for functional performance, CIRP Annals - Manufacturing Technology 57 (2008) 750-769.

73. M. Wakuda, Y. Yamauchi, S. Kanzaki, Y. Yasuda, Effect of surface texturing on friction reduction between ceramic and steel materials under lubricated sliding contact, Wear 254 (2003) 356-363.

74. P. Andersson, J. Koskinen, S. Varjus, Y. Gerbig, H. Haefke, S. Georgiou, B. Zhmud, W. Buss, Microlubrication effect by laser-textured steel surfaces, Wear 262 (2007) 369-379.

75. E. Gualtieri, A. Borghi, L. Calabri, N. Pugno, S. Valeri, Increasing nanohardness and reducing friction of nitride steel by laser surface texturing, Tribology International 42 (2009) 699-705.

76. B. Kim, Y.H. Chae, H.S. Choi, Effects of surface texturing on the frictional behaviour of cast iron surfaces, Tribology International 70 (2014) 128-135.

77. H.L. Costa, I.M. Hutchings, Effect of die surface patterning on lubrication in strip, Journal of Materials Processing Technology 209 (2009) 1175-1180.

78. Z.M. Hu, T.A. Dean, A study of surface topography, friction and lubricants in metalforming, International Journal of Machine Tools and Manufacture 40 (2000) 1637-1649.

79. T. Sugihara, T. Enomoto, Development of a cutting tool with a nano/micro-textured surface-improvement of anti-adhesive effect by considering the texture patterns, Precision Engineering 33 (2009) 425-429.

80. D.E. Kim, K.H. Cha, I.H. Sung, Design of surface microstructures for friction control in micro-systems application, CIRP Annals - Manufacturing Technology 51 (2002) 495-498.

81. I. Shimizu, J.L. Andreasen, J.I. Bech, N. Bay, Influence of workpiece surface topography on the mechanisms of liquid lubrication in strip drawing, Journal of Tribology 123 (2001) 290-294.

82. N. Krishnan, Friction in microforming, Encyclopedia of Tribology, Springer, 2013, pp. 1334-1338.

83. D. Wang, H. Yang, H. Li, Advance and trend of friction study in plastic forming, Transactions of Nonferrous Metals Society of China 24 (2014) 1263-1272. 